\title{
$\alpha$-Catenin interacts with APC to regulate $\beta$-catenin proteolysis and transcriptional repression of Wnt target genes
}

\author{
Seung H. Choi ${ }^{1}$ Conchi Estarás, ${ }^{1}$ James J. Moresco, ${ }^{2}$ John R. Yates III, $^{2}$ and Katherine A. Jones ${ }^{1,3}$ \\ ${ }^{1}$ Regulatory Biology Laboratory, The Salk Institute for Biological Studies, La Jolla, California 92037 USA; ${ }^{2}$ Department \\ of Chemical Physiology and Cell Biology, The Scripps Research Institute, La Jolla, California 92037, USA
}

\begin{abstract}
Mutation of the adenomatous polyposis coli (APC) tumor suppressor stabilizes $\beta$-catenin and aberrantly reactivates Wnt/ $\beta$-catenin target genes in colon cancer. APC mutants in cancer frequently lack the conserved catenin inhibitory domain (CID), which is essential for $\beta$-catenin proteolysis. Here we show that the APC CID interacts with $\alpha$-catenin, a Hippo signaling regulator and heterodimeric partner of $\beta$-catenin at cell:cell adherens junctions. Importantly, $\alpha$-catenin promotes $\beta$-catenin ubiquitylation and proteolysis by stabilizing its association with APC and protecting the phosphodegron. Moreover, $\beta$-catenin ubiquitylation requires binding to $\alpha$-catenin. Multidimensional protein identification technology (MudPIT) proteomics of multiple Wnt regulatory complexes reveals that $\alpha$-catenin binds with $\beta$-catenin to LEF-1/TCF DNA-binding proteins in Wnt3a signaling cells and recruits APC in a complex with the CtBP:CoREST:LSD1 histone H3K4 demethylase to regulate transcription and $\beta$-catenin occupancy at Wnt target genes. Interestingly, tyrosine phosphorylation of $\alpha$-catenin at Y177 disrupts binding to APC but not $\beta$-catenin and prevents repression of Wnt target genes in transformed cells. Chromatin immunoprecipitation studies further show that $\alpha$-catenin and APC are recruited with $\beta$-catenin to Wnt response elements in human embryonic stem cells (hESCs). Knockdown of $\alpha$-catenin in hESCs prevents the switch-off of Wnt/ $\beta$-catenin transcription and promotes endodermal differentiation. Our findings indicate a role for $\alpha$-catenin in the APC destruction complex and at Wnt target genes.
\end{abstract}

[Keywords: Wnt signaling; $\beta$-catenin; $\alpha$-catenin; APC tumor suppressor; CtBP:RCOR1:LSD1; transcription]

Supplemental material is available for this article.

Received August 19, 2013; revised version accepted October 9, 2013.

Mutation of the adenomatous polyposis coli (APC) tumor suppressor is an early step in most sporadic colon cancers, and $A P C$ mutations in inherited familial adenomatous polyposis (FAP) lead to early onset of the disease (Aoki and Taketo 2007; McCartney and Näthke 2008). APC localizes to the cell membrane, actin cytoskeleton, mitotic spindle, and nucleus to regulate cell polarity, adhesion, and migration and the state of the epigenome (Caldwell and Kaplan 2009; Lui et al. 2012; Hammoud et al. 2013). APC also controls intestinal epithelial cell homeostasis as a negative regulator of the canonical Wnt signaling pathway (Stamos and Weis 2013). In the absence of Wnt signaling, APC functions in a proteolytic destruction complex with the Axin scaffold protein to control the turnover of $\beta$-catenin, a transcriptional coactivator of the Wnt pathway and a core subunit of cell:cell adherens junctions (Clevers and Nusse 2012). Within this complex, Axin facilitates $\beta$-catenin phosphorylation by

${ }^{3}$ Corresponding author

E-mail jones@salk.edu

Article is online at http://www.genesdev.org/cgi/doi/10.1101/gad.229062.113. casein kinase 1 (CK1) at S45 and glycogen synthase kinase $3 \beta$ (GSK3 $\beta$ ) at S33/S37/T41 to create a phosphodegron recognized by the Skp1/Cull/F-box ${ }^{\beta \operatorname{TrCP}}(\beta \operatorname{TrCP})$ E3 ubiquitin (Ub) ligase complex. Phosphorylated $\beta$-catenin is then transferred from Axin to APC, which shields the $\beta$-catenin phosphodegron from the PP2A phosphatase $(\mathrm{Ha}$ et al. 2004; Su et al. 2008) and promotes its ubiquitylation and degradation. In signaling cells, Wnt ligands bind to Frizzled and low-density lipoprotein receptor-related protein 5/6 (Lrp5/6) cell surface receptors and disrupts association of $\beta \operatorname{TrCP}$ with the Axin destruction complex (Li et al. 2012) or, alternatively, releases $\beta$-catenin from Axin (Kim et al. 2013) to prevent destruction. The newly stabilized $\beta$-catenin then enters the nucleus and associates with LEF-1/TCF HMG proteins to activate canonical Wnt

(C) 2013 Choi et al. This article is distributed exclusively by Cold Spring Harbor Laboratory Press for the first six months after the full-issue publication date (see http://genesdev.cshlp.org/site/misc/terms.xhtml). After six months, it is available under a Creative Commons License (Attribution-NonCommercial 3.0 Unported), as described at http:// creativecommons.org/licenses/by-nc/3.0/. 
target genes, including $M Y C, C C N D 1$, and AXIN2 (Valenta et al. 2012).

APC is a multidomain scaffold protein containing seven armadillo (ARM) repeats, three 15-amino-acid repeats (15Rs), seven 20-amino-acid repeats (20Rs), a catenin inhibitory domain (CID/segment B), three SAMP repeats, a site for EB1 (end-binding protein-1) binding and microtubule attachment, and a C-terminal PDZbinding domain (Stamos and Weis 2013). The presence or absence of the CID in APC mutants may serve to finetune Wnt signaling to levels that are optimal for tumor formation in different tissues (Kohler et al. 2009). Most colon cancers express APC C-terminal truncation mutants that contain the 15Rs and 20R1 but lack the 20R2CID region. The 20R2-CID domain is highly conserved and plays a critical role in APC-directed proteolysis of $\beta$-catenin (Roberts et al. 2011). However $\beta$-catenin does not bind to the APC 20R2-CID domain, and its function in proteolysis is unclear.

At cell-cell adherens junctions, $\beta$-catenin interacts with $\alpha$-catenin, which connects the actin cytoskeleton to the adhesion complex (Stamos and Weis 2013). Unlike $\beta$-catenin, which functions as an oncogene, $\alpha$-catenin is a potent tumor suppressor for breast and colon cancer, and its down-regulation or loss in aggressive and late stage cancers is correlated with metastasis (Vasioukhin et al. 2001; Benjamin and Nelson 2008). In addition to its role in cell adhesion, $\alpha$-catenin inhibits signaling through the Wnt, Ras, NF-кB, and Hedgehog pathways. Recent studies have identified a key role for $\alpha$-catenin in the Hippo kinase cascade (Schlegelmilch et al. 2011; Silvis et al. 2011), which controls organ size and cell contact inhibition through the Yes-associated protein YAP1. YAP1 is a potent coactivator in many signaling systems and also functions with $\beta$-catenin in TBX5 complexes to regulate anti-apoptotic genes in colon cancer (Rosenbluh et al. 2012). At high cell density, phosphorylated YAP1 accumulates in the cytoplasm, where it is sequestered by $\alpha$-catenin and inhibits Wnt signaling (Imajo et al. 2012). The YAP1 homolog TAZ is degraded by the APC complex and is required for expression of many Wnt target genes (Azzolin et al. 2012). Mechanistic studies of YAP1 function in TGFB/SMAD signaling further reveal that it both stimulates transcription and promotes the exchange of coactivator and corepressor complexes at target genes (Alarcón et al. 2009; Aragon et al. 2011). Thus, $\alpha$-catenin links cell adhesion signals to YAP1 inactivation and the inhibition of cell proliferation.

In the nucleus, $\beta$-catenin interacts with LEF-1/TCF DNA-binding proteins and activates Wnt target genes through a unique $\mathrm{C}$-terminal activation domain. The $N$-terminal ARM repeat of $\beta$-catenin associates with BCL9/Legless and Pygopus, a PHD finger protein that binds $\mathrm{H} 3 \mathrm{~K} 4 \mathrm{me} 2$ and promotes $\mathrm{H} 3 \mathrm{~K} 4 \mathrm{me} 3$ at target gene promoters (Clevers and Nusse 2012; Valenta et al. 2012). We previously showed that APC is also recruited to Wnt target genes upon activation of the pathway and regulates the periodic exchange of $\beta$-catenin and TLE1/Gro corepressor complexes (Sierra et al. 2006). This activity is lost in APC mutant colon cancer cells, and re-expression of full-length APC leads to transcriptional repression, loss of $\mathrm{H} 3 \mathrm{~K} 4 \mathrm{me} 3$, and rapid release of $\beta$-catenin from the LEF-1/TCF complex at target genes. Because APC competes with LEF-1 for binding to $\beta$-catenin, it is unclear how it is selectively targeted to Wnt response elements (WREs) in vivo.

To further understand the role of APC in Wnt signaling, we analyzed the composition of several Wnt regulatory complexes using multidimensional protein identification technology (MudPIT). Here we report that $\alpha$-catenin associates with the APC tumor suppressor. This interaction is mediated through the CID, a major hot spot for APC deletions in colon cancer. Importantly, $\alpha$-catenin controls phosphorylation and Ub-dependent proteolysis of $\beta$-catenin through the APC destruction complex. In addition, we show that $\alpha$-catenin binds with $\beta$-catenin to LEF-1/TCF DNA-binding proteins and recruits APC in a complex with CtBP:LSD1 to repress transcription and control $\beta$-catenin occupancy at target genes. Lentiviral shRNA-mediated knockdown of $\alpha$-catenin results in a failure to switch off Wnt target genes in signaling human embryonic stem cells (hESCs), which leads to differentiation and up-regulation of endoderm-specific genes. These findings indicate an unsuspected role for $\alpha$-catenin in APC-regulated transcriptional repression and proteolytic destruction of $\beta$-catenin.

\section{Results}

MudPIT proteomics analysis of $\alpha$-catenin, $\beta$-catenin, $A P C$, and LEF-1/TCF complexes

To examine the composition of Wnt regulatory complexes, stable HEK293 cell lines expressing Flag-tagged human $\alpha$-catenin, $\beta$-catenin, LEF-1, and TCF4 were isolated for affinity purification and MudPIT analysis. Because ectopic expression of APC inhibits cell growth, we used a truncated Flag:APC (amino acids 1-2227) protein that retains the $3 \times 15 \mathrm{R}$, CID, $7 \times 20 \mathrm{R}$, and SAMP repeats. Mass spectrometry analysis of affinity-purified Flag:APC (amino acids 1-2227) complexes (Fig. 1A; Supplemental Fig. S1A,B) revealed strong binding to the CtBP complex, including CtBP, REST corepressor 1 (RCOR1), and LSD1 H3K4me1/2 demethylase. In addition, we detected GNB2L1/RACK1, $\alpha$-catenin (CTNNA1), proteasome subunits, and low levels of $\beta$-catenin (CTNNB1) but not Axin. The strong association of $\alpha$-catenin, CtBP, and LSD1 with native APC complexes was confirmed by immunoblot (Fig. 1B).

Previous studies detected $\alpha$-catenin in the APC destruction complex (Su et al. 1993; Layton et al. 2012), but it is not known to have a functional role. Because indirect binding of $\alpha$-catenin to APC would not explain its prevalence in the complex, we asked whether $\beta$-catenin is required for $\alpha$-catenin to associate with APC. Both $\alpha$-catenin and $\beta$-catenin were readily detected in native APC complexes from HEK293 cells treated with control siRNA. Interestingly, $\alpha$-catenin and CtBP remained in the APC complex upon knockdown of $\beta$-catenin (Fig. 1C). Surprisingly, in the converse experiment, binding 
A

\begin{tabular}{|c|c|c|}
\hline \multicolumn{3}{|c|}{ FLAG:APC (aa 1-2227) } \\
\hline Protein ID & Pep \# & Cvg (\%) \\
\hline APC & 663 & 38.8 \\
\hline CtBP1 & 50 & 34.3 \\
\hline CtBP2 & 57 & 28.5 \\
\hline PSMD4 & 7 & 28.4 \\
\hline CTNNA1 & 24 & 24.1 \\
\hline RUVBL2 & 11 & 19.2 \\
\hline RCOR1 & 6 & 16.2 \\
\hline LSD1 & 14 & 15.7 \\
\hline HDAC2 & 4 & 12.5 \\
\hline CTNNB1 & 11 & 7.7 \\
\hline CTNNA2 & 6 & 6.2 \\
\hline
\end{tabular}

D

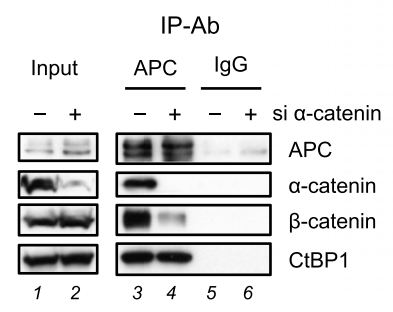

E

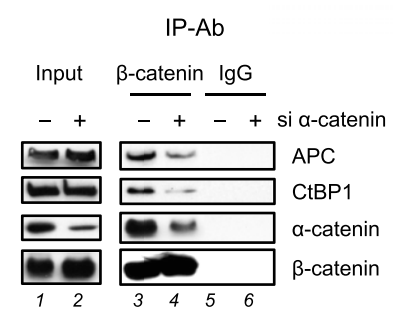

B



F

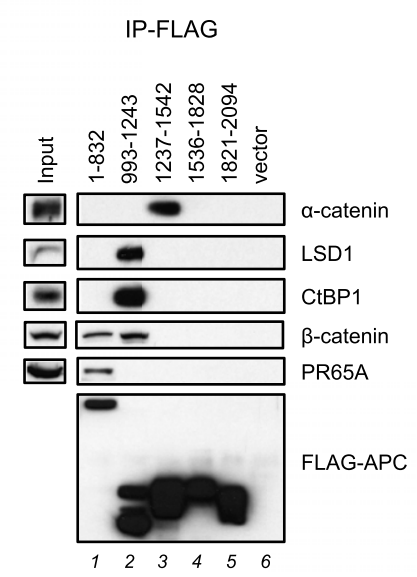

$\alpha$-Catenin interacts with the APC tumor suppressor

C

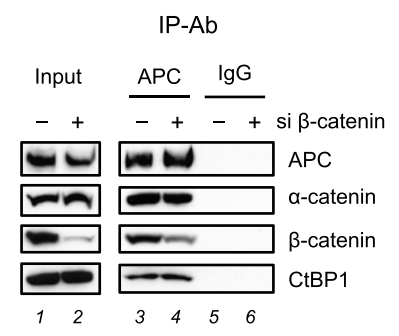

G

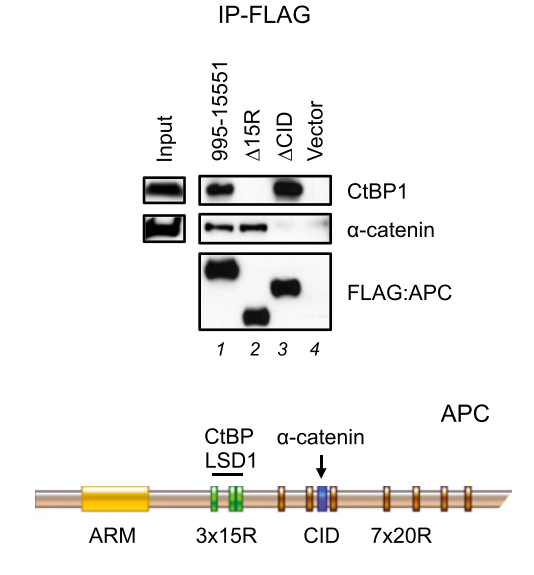

Figure 1. $\alpha$-Catenin interacts with the APC CID. (A) MudPIT analysis of the affinity-purified Flag:APC complex from HEK293 cells. (B) Immunoblot/co-IP analysis of the native APC complex from whole-cell HEK293 lysates using antisera indicated at the right of each panel. (C) Immunoblot/co-IP analysis of the native APC complex in HEK293 cells treated with control-specific or $\beta$-catenin-specific siRNAs. (D) Immunoblot/co-IP analysis of the native APC complex in HEK293 cells treated with controlspecific or $\alpha$-catenin-specific siRNAs. (E) Immunoblot/co-IP analysis of the native $\beta$-catenin complex in HEK293 cells treated with control-specific or $\alpha$-catenin-specific siRNAs. $(F)$ Factor interaction site mapping by immunoblot (co-IP) analysis of transfected Flag:APC fragments in HEK293 cells. $(G)$ Factor interaction site mapping by immunoblot (co-IP) analysis of transfected Flag:APC in-frame deletion mutants in HEK293 cells. The APC-binding sites for CtBP:LSD1 and $\alpha$-catenin are shown in the schematic diagram.

of $\beta$-catenin to APC was significantly reduced in $\alpha$-catenin knockdown cells (Fig. 1D), whereas the binding of CtBP was unaffected. Thus, $\alpha$-catenin selectively stabilizes the binding of $\beta$-catenin to the APC complex. Similarly, depletion of $\alpha$-catenin reduced the association of APC and CtBP with $\beta$-catenin (Fig. 1E). In contrast to current models, these data strongly suggest that $\alpha$-catenin helps tether $\beta$-catenin to the APC destruction complex.

Although $\beta$-catenin can bind APC directly through the $3 \times 15 R$ or GSK3 $\beta$-phosphorylated 7x20R domain (Stamos and Weis 2013), $\beta$-catenin destruction does not require the $3 \times 15 \mathrm{R}$ domain and is instead mediated by the APC 20R2-CID domain (Kohler et al. 2009; Roberts et al. 2011). Because $\beta$-catenin does not interact directly with 20R 2 or the CID, it remains unclear how it is targeted to the APC complex for destruction.

\section{$\alpha$-Catenin interacts with the APC CID}

To investigate how $\alpha$-catenin recognizes APC, partially overlapping Flag:APC fragments were expressed in HEK293 cells and analyzed by coimmunoprecipitation (co-IP) to map the binding site. As shown previously, exogenously expressed $\beta$-catenin binds weakly to the APC $3 \times 15 \mathrm{R}$ and ARM domains. However, CtBP and LSD1 bound much more strongly to the $3 \times 15 R$ fragment (Fig. 1F) and therefore may exclude binding of $\beta$-catenin to this site in the endogenous APC complex. Of note, $\alpha$-catenin did not recognize the $3 \times 15 \mathrm{R}$ fragment but bound instead to an adjacent fragment containing 20R1-R3 repeats and the CID (amino acids 1237-1542). Further mapping with a larger APC fragment (amino acids 995-1551) containing either the wild-type sequence or precise in-frame deletions of the $3 \times 15 R, 20 R 2$, or CID domains established 
that $\alpha$-catenin recognizes the 62-amino-acid CID motif, whereas CtBP, RCOR1, and LSD1 interact with the $3 \times 15 R$ domain (Fig. 1G; Supplemental Fig. S1C,D). We did not detect binding of $\beta$-catenin to Flag:APC (amino acids 9951551) under the stringent conditions used in this experiment. We conclude that $\alpha$-catenin targets the CID and helps to stabilize the association of $\beta$-catenin with the APC complex. Because the APC CID is essential for $\beta$-catenin ubiquitylation and proteolysis (Kohler et al. 2009; Roberts et al. 2011), these findings strongly suggested a possible functional role for $\alpha$-catenin in the destruction complex.

\section{$\alpha$-Catenin regulates $\beta$-catenin ubiquitylation} and proteolysis

One critical role for APC is to protect the $\beta$-catenin phosphodegron from dephosphorylation by the PP2A phosphatase (Su et al. 2008), which promotes ubiquitylation by preserving the binding site for $\beta \operatorname{TrCP} 1$. To address whether $\alpha$-catenin contributes to this process, $\beta$-catenin was transiently induced in HEK293 cells using the GSK3 $\beta$ inhibitor Factor XV (Atilla-Gokcumen et al. 2006), and the ubiquitylated proteins were detected following withdrawal of Factor XV in the presence of the protease inhibitor MG132. High-molecular-weight Ub-conjugated $\beta$-catenin complexes were visualized by immunoblot of anti-Ub immunoprecipitates (Fig. 2A). Importantly, ubiquitylation of native $\beta$-catenin was strongly inhibited in $\alpha$-catenin-depleted cells, similar to that observed in APC knockdown cells. Knockdown of APC or $\alpha$-catenin also reduced $\beta$-catenin S33 phosphorylation (Fig. 2A). Thus, $\alpha$-catenin functions within the APC destruction complex to facilitate the ubiquitylation of $\beta$-catenin.
A

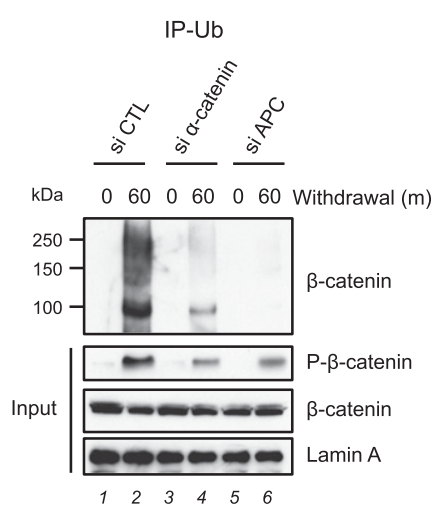

D

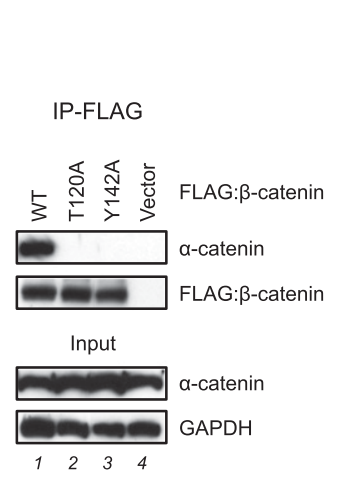

$E$
B

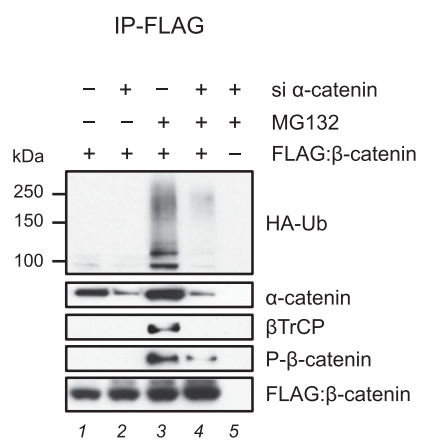

C

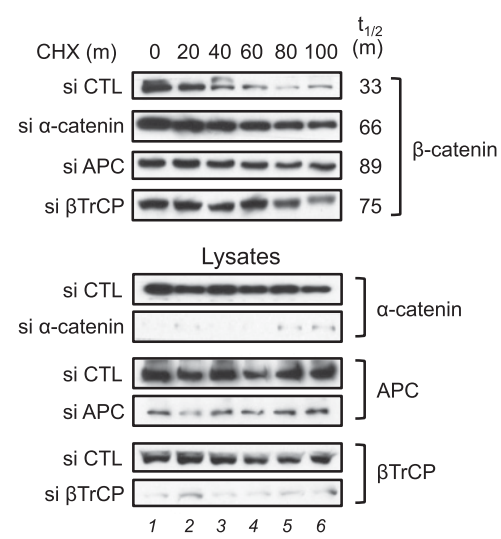

IP-FLAG

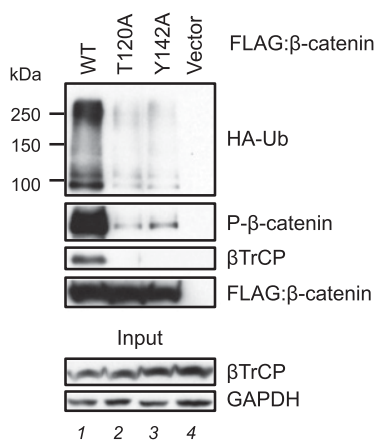

$\mathrm{F}$

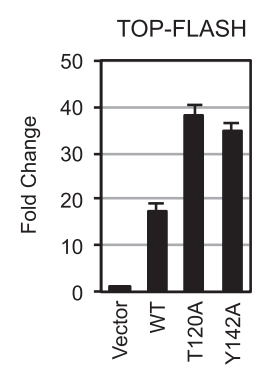

G

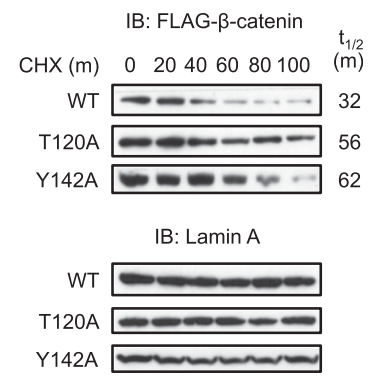

Figure 2. $\alpha$-Catenin facilitates $\beta$-catenin proteolysis by the APC destruction complex. $(A)$ Immunoblot of anti-Ub immunoprecipitates for $\beta$-catenin and S33-phosphorylated $\beta$-catenin (P- $\beta$-catenin) from nuclear extracts of HEK293 cells treated with control-specific (si CTL), $\alpha$-catenin-specific (si $\alpha$-catenin), or APC-specific (si APC) siRNAs. Following 48 h of incubation with each siRNA, $\beta$-catenin was induced for $12 \mathrm{~h}$ with $10 \mathrm{nM}$ Factor XV, and cells were incubated in fresh medium containing MG132 for the times indicated above each lane. (B) Immunoblot and co-IP analysis of transfected Flag: $\beta$-catenin from HEK293 cells treated with control-specific or $\alpha$-catenin-specific siRNAs. Cells were cotransfected with HA-Ub and treated with MG132 as indicated. $(C)$ Measurement of the half-life ( $\left.t_{1 / 2}\right)$ of native $\beta$-catenin in nuclear extracts. HEK293 cells were incubated with CHX for the indicated times and transfected with control-specific (si CTL), $\alpha$-catenin-specific, APC-specific, or $\beta$ TrCP-specific siRNAs as indicated. The knockdown efficiency of each siRNA was assessed by immunoblot in the bottom panel (Lysate). $(D)$ Immunoblot/co-IP of wild-type and point mutant (T120A and Y142A) Flag: $\beta$-catenin expressed in HEK293 cells. (E) Immunoblot/co-IP of wild-type and point mutant (T120A and Y142A) Flag: $\beta$-catenin expressed in HEK293 cells. Cells were cotransfected with HA-Ub and treated with MG132. $(F)$ TOP-FLASH reporter gene analysis of wild-type and point mutant (T120A and Y142A) Flag: $\beta$-catenin activity in transfected HEK293 cells. $(G)$ Measurement of the half-life $\left(t_{1 / 2}\right)$ of wild-type and point mutant Flag: $\beta$-catenin proteins in nuclear extracts. Transfected HEK293 cells were incubated with CHX for the indicated times. 
To confirm these findings, Flag-tagged $\beta$-catenin was cotransfected with HA-tagged Ub (HA-Ub) in cells treated with control-specific or $\alpha$-catenin-specific siRNA, and the ubiquitylated protein was visualized by immunoblot of Flag: $\beta$-catenin immunoprecipitates with anti-HA antibody (Fig. 2B). Importantly, the level of HA-Ub-conjugated $\beta$-catenin was dramatically reduced in $\alpha$-catenin-depleted cells. Immunoblot with a phospho-specific antibody further showed reduced $\beta$-catenin S33 phosphorylation and binding to $\beta \operatorname{TrCP} 1$ in these cells. These data indicate that $\alpha$-catenin promotes ubiquitylation in part by protecting the $\beta$-catenin phosphodegron and association with $\beta \operatorname{TrCP} 1$.

To determine whether $\alpha$-catenin affects $\beta$-catenin protein stability, de novo protein synthesis was blocked using the translation inhibitor cycloheximide (CHX). Immunoblot of $\beta$-catenin at different time points revealed a half-life of $\sim 33 \mathrm{~min}$ for the native protein in HEK293 cells (Fig. 2C; Supplemental Fig. S2A). Interestingly, knockdown of $\alpha$-catenin extended the half-life of $\beta$-catenin to an extent similar to that observed in cells depleted of APC or $\beta$ TrCP1, whereas $\beta$-catenin stability was unaffected by a control siRNA. The knockdown efficiency for each protein was confirmed by immunoblot. We conclude that $\alpha$-catenin is required for APC-regulated ubiquitylation and proteolysis of $\beta$-catenin.

\section{$\beta$-Catenin proteolysis requires binding to $\alpha$-catenin}

$\alpha$-Catenin binds to the $\beta$-catenin $\mathrm{N}$ terminus (amino acids 118-146) near the phosphodegron (Stamos and Weis 2013). To address whether this interaction is required for $\beta$-catenin proteolysis, we identified two point mutations in this region (T120A and Y142A) that destroy binding to $\alpha$-catenin in co-IP experiments (Fig. 2D). Coexpression of these proteins with HA-Ub in MG132-treated cells revealed that both mutations greatly impair $\beta$-catenin ubiquitylation without affecting overall protein expression (Fig. 2E). Moreover, these mutants were defective for S33 phosphorylation and binding to $\beta \operatorname{TrCP} 1$ (Fig. 2E) and were more active than wild-type $\beta$-catenin in the TOPFLASH reporter assay (Fig. 2F). Immunoblot analysis of the Flag: $\beta$-catenin protein levels in nuclear extracts from CHX-treated cells revealed that the half-life of each mutant was significantly higher than the wild-type protein (Fig. 2G; Supplemental Fig. S2B). Thus, binding of $\beta$-catenin to $\alpha$-catenin is also necessary for Ub-dependent proteolysis by the APC complex.

\section{$\alpha$-Catenin tyrosine phosphorylation at Y177 disrupts binding to APC}

In parallel, we also mapped the domain of $\alpha$-catenin required for binding to APC. $\beta$-Catenin recognizes an $\alpha$-helical motif at the $\mathrm{N}$ terminus of $\alpha$-catenin (amino acids 117-143) (Huber et al. 1997), and we found that $\mathrm{N}$-terminal truncation of $\alpha$-catenin ( $\Delta$ amino acids $1-128$ ) eliminated binding to $\beta$-catenin in co-IP experiments (Fig. 3A). Interestingly, this mutant retained the ability to bind APC, confirming that $\alpha$-catenin can bind APC independently of $\beta$-catenin. However, further truncation of $\alpha$-catenin to amino acid 189 destroyed the binding to
APC, indicating that $\beta$-catenin and APC recognize adjacent sites within the $\alpha$-catenin VH1 domain. Inspection of a global phosphoproteomics database (http://www. phosphosite.org) indicates that this region includes a major site of $\alpha$-catenin tyrosine phosphorylation (Y117) in multiple transformed cell lines. Consistent with this possibility, endogenous $\alpha$-catenin immunoprecipitates and purified Flag: $\alpha$-catenin fractions from HEK293 cells were readily detected by immunoblot with an antiphosphotyrosine-specific antibody, and the signal was enhanced by serum (Fig. 3B). Moreover, a point mutation at this site $(\mathrm{Y} 177 \mathrm{~F})$ blocked phosphorylation without affecting overall protein expression (Fig. 3B, top panel), and phosphorylation was also inhibited in a dose-dependent manner by a Src family kinase inhibitor, Dasatinib (Fig. 3B, bottom panel). Thus, Y177 is a prominent site of $\alpha$-catenin tyrosine phosphorylation in vivo.

To address whether tyrosine phosphorylation affects binding to APC, co-IP experiments were carried out with the Flag-tagged $\alpha$-catenin wild-type and Y177F proteins. Remarkably, the $\alpha$-catenin Y177F mutation enhanced binding to APC without affecting the interaction with $\beta$-catenin (Fig. 3A). Thus, Y177 phosphorylation significantly inhibits binding of $\alpha$-catenin to APC in HEK293 cells. In support of this finding, the Y177F mutant was also a more potent repressor of $\mathrm{Wnt} / \beta$-catenin transactivation in the TOP-FLASH reporter assay (Fig. 3C) and at endogenous Wnt target genes (Fig. 3D). Similarly, Dasatinib enhanced the binding of $\alpha$-catenin to APC (Supplemental Fig. S3A) and transcriptional repression (Supplemental Fig. S3B). Further analysis revealed that point mutation of the residue adjacent to Y177, Q176 (Q176A), reduced binding of $\alpha$-catenin to APC in co-IP experiments and disrupted transcription repression in vivo (Fig. 3E,F). In cellular proliferation assays, ectopic $\alpha$-catenin Y177F strongly suppressed cell growth, whereas the Q176A mutant did not (Supplemental Fig. S3C). K178 mutation (K178A) had only a modest effect. Thus, $\alpha$-catenin Y177 phosphorylation disrupts binding to APC and further enhances $\beta$-catenin transactivation in transformed cells.

\section{$\alpha$-Catenin binds with $\beta$-catenin to LEF-1/TCF complexes in Wnt3a signaling cells}

We previously showed that APC accompanies $\beta$-catenin target genes to switch off transcription and signaling at the gene (Sierra et al. 2006). Because $\beta$-catenin:LEF-1/TCF complexes cannot bind APC directly, it is unclear how APC is specifically targeted to WREs. Our current findings suggested that APC can target $\beta$-catenin indirectly through $\alpha$-catenin. Although $\beta$-catenin is widely considered to bind LEF-1/TCF as a monomer, $\alpha$-catenin has been detected in the nucleus and is a potent repressor of Wnt target genes in transformed cells (Benjamin and Nelson 2008).

To examine the composition of LEF-1/TCF and $\beta$-catenin complexes, Flag: $\beta$-catenin, Flag:LEF-1, and Flag:TCF4 complexes were affinity-purified from stable HEK293 cell lines in the absence and presence of Factor $\mathrm{XV}$, which 
Choi et al.

A

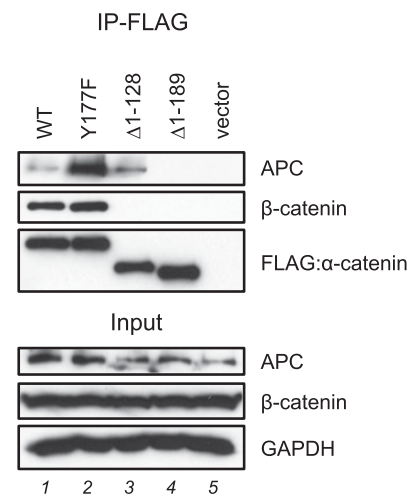

B



C

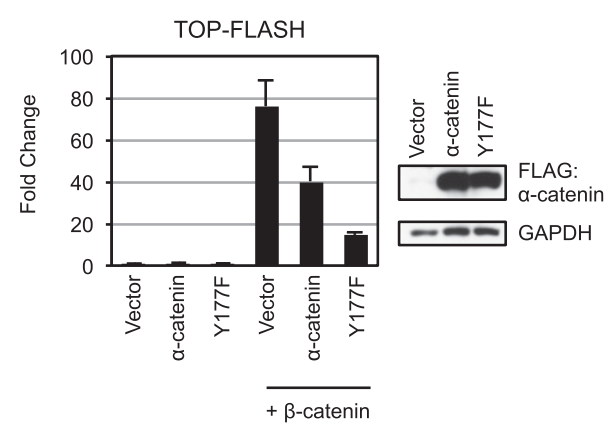

F
D



E

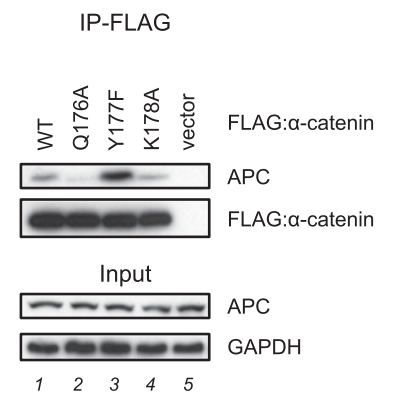

TOP-FLASH

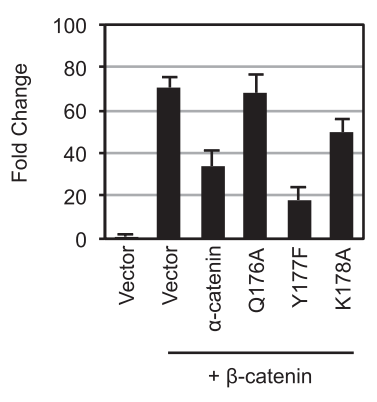

Figure 3. Tyrosine phosphorylation of $\alpha$-catenin regulates binding to APC. (A) Immunoblot/co-IP analysis of wild-type (WT) or mutant Flag: $\alpha$-catenin in HEK293 cells cultured in $10 \%$ serum using antisera indicated at the right of each panel. (B) Immunoblot of wild-type (WT) or Y177F mutant Flag: $\alpha$-catenin in HEK293 cells. (Top panel) Where indicated, cells were incubated for $24 \mathrm{~h}$ in $0.1 \%(-)$ or $10 \%(+)$ serum. (Bottom panel) Immunoblot analysis of native $\alpha$-catenin with anti-P-Tyr antisera from HEK293 cells (10\% serum). Cells were treated with Dasatinib as indicated. The domain structure of human $\alpha$-catenin is shown at the bottom. (C) Repression of TOP-FLASH reporter gene activity in transfected HEK293 cells expressing wild-type (WT) or point mutant (Y177F) Flag: $\alpha$-catenin. Where indicated, cells were cotransfected with a $\beta$-catenin expression vector. $\alpha$-Catenin expression was measured in the immunoblot at the right. $(D)$ Repression of endogenous Wnt target genes by wild-type (WT) and Y177F $\alpha$-catenin in HCT116 cells. mRNA levels were measured by qRT-PCR. (E) Immunoblot/co-IP of wild-type and point mutants (Q176A, Y177F, and K178A) that Flag: $\alpha$-catenin expressed in HEK293 cells. (F) TOP-FLASH reporter gene analysis of wild-type and point mutant (Q176A, Y177F, and K178A) Flag: $\alpha$-catenin toward $\beta$-catenin activity in transfected HEK293 cells.

stabilizes and promotes nuclear entry of $\beta$-catenin. The purified complexes were subjected to MudPIT, and interacting proteins were ranked by relative abundance according to peptide spectral counts (Fig. 4A; Supplemental Fig. S4A). Nonspecific proteins detected in mock Flag immunoprecipitations from parental HEK293 cells or in preparations of unrelated Flag-tagged proteins were excluded from further consideration. The highest-ranked proteins in the Flag: $\beta$-catenin MudPIT data set included $\alpha$-catenin, the CTNNBIP1/ICAT inhibitor, cadherins, actin cytoskeletal proteins, APC destruction complex components (APC, Axin1, GNB2L1/RACK1, GSK3 $\beta$, CK1 $\alpha 1$, CtBP1, and CtBP2), and the HMG DNA-binding proteins TCF7L2/TCF4 and LEF-1 (Fig. 4A; Supplemental Fig. S4A).

In parallel, affinity-purified Flag:LEF-1 and Flag:TCF4 complexes isolated from mock-treated or Factor XV- treated cells were also subjected to MudPIT. As expected, $\beta$-catenin was highly enriched in the Flag:LEF-1 and Flag:TCF4 fractions isolated from Factor XV-stimulated cells. Surprisingly, however, these fractions also contained very high levels of $\alpha$-catenin. In contrast, other $\beta$-catenin-interacting proteins, including CTNNBP1/ ICAT and cadherins, were not found in the LEF-1/TCF4 complexes. Like $\beta$-catenin, $\alpha$-catenin was not detected in the LEF-1 and TCF4 complexes in the absence of signaling. Strikingly, near-stoichiometric levels of $\alpha$-catenin and $\beta$-catenin could also observed by SDS-PAGE and silver staining (Fig. 4B), and the strong signal-dependent interaction was confirmed by immunoblot (Fig. 4C; Supplemental Fig. S4B) of Flag:LEF-1 and Flag:TCF4 complexes purified from Factor XV-treated cells. The association of $\alpha$-catenin with Flag:LEF-1 was eliminated in $\beta$-catenin 
A

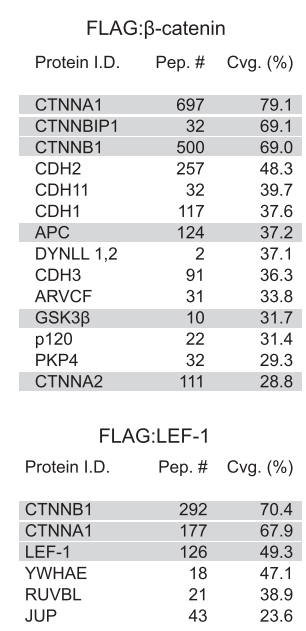

D

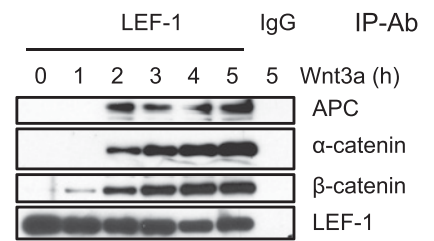

Nuclear Extract

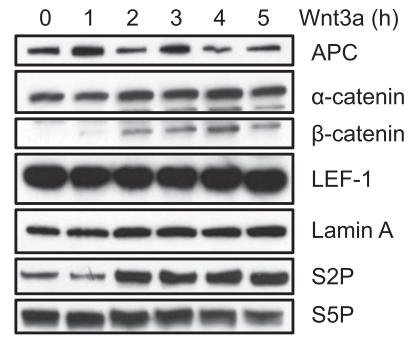

B

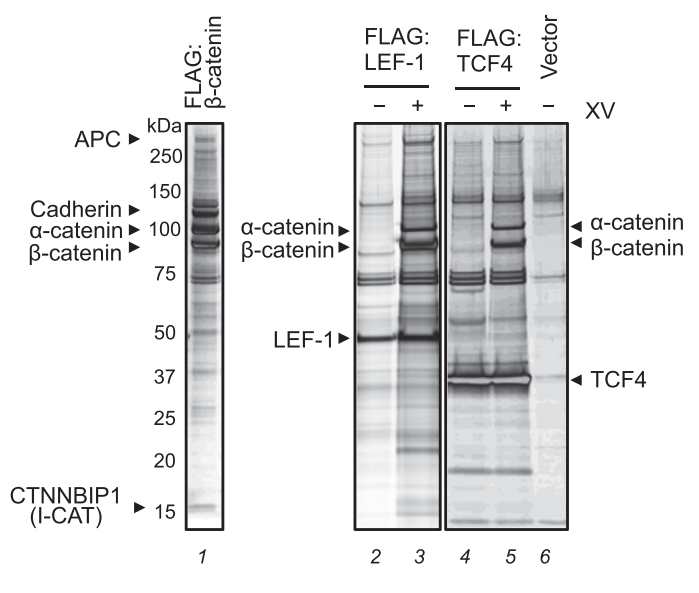

C

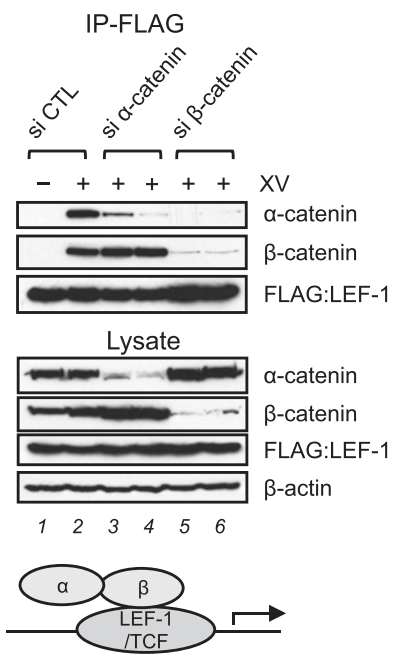

$\mathrm{E}$
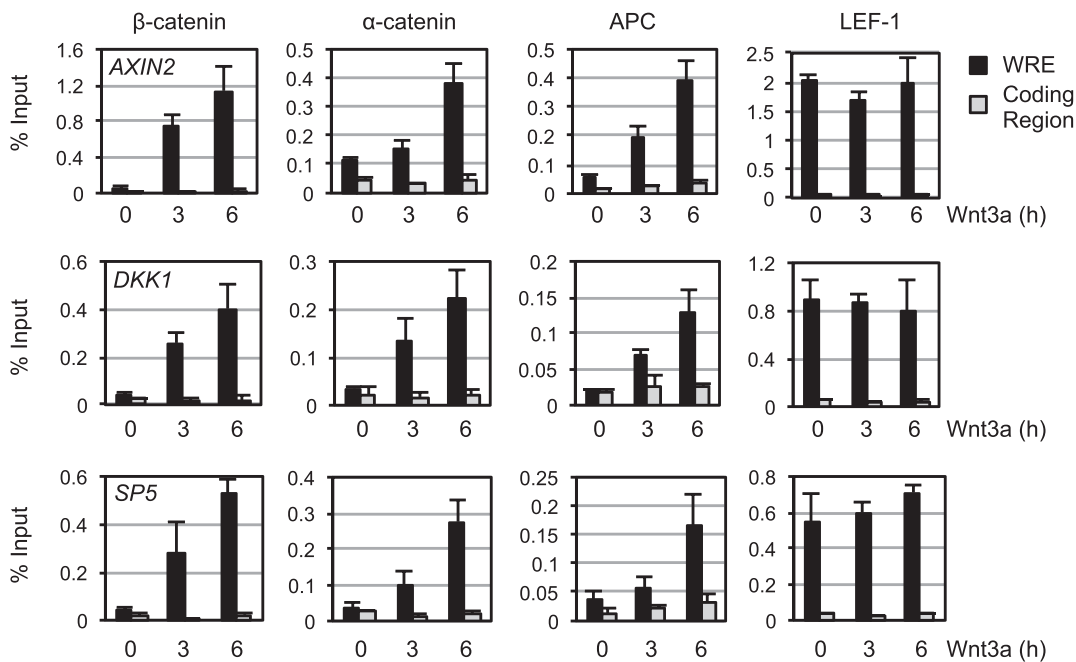

Figure 4. $\beta$-Catenin recruits the $\alpha$-catenin:APC complex to LEF-1/TCF complexes. (A) MudPIT analysis of affinity-purified Flag: $\beta$-catenin and Flag:LEF-1 complexes isolated from HEK293 cells without and with $100 \mathrm{nM}$ Factor XV, respectively. Shown is a subset of the identified interacting proteins ranked in abundance according to the total number of peptides identified by mass spectrometry and the percentile of protein sequence coverage. (B) SDS-PAGE and silver stain analysis of Flag: $\beta$-catenin, Flag:LEF-1, and Flag:TCF4 complexes isolated from untreated and $100 \mathrm{nM}$ Factor XV-induced HEK293 cells, as indicated. $(C)$ Immunoblot/co-IP analysis of Flag:LEF-1 complexes affinity-purified from HEK293 cells transfected with control-specific (si CTL), $\alpha$-catenin-specific, or $\beta$-cateninspecific siRNAs. (Bottom panels) The knockdown efficiency of each siRNA was analyzed by immunoblot of the lysate. Where indicated, cells were treated for $4 \mathrm{~h}$ with $100 \mathrm{nM}$ Factor XV. (D) Immunoblot time-course analysis of native LEF-1 immunoprecipitates in Wnt3a signaling HEK293 cells. Cells were incubated with Wnt3a-conditioned medium for the times indicated. Immunoblot analysis of the input nuclear fraction is shown in the bottom panels. (E) ChIP analysis of the AXIN2, DKK1, or SP5 genes in HEK293 cells treated with Wnt3a-conditioned medium for the indicated times. Factor occupancy at the WRE (black) or coding (gray) regions was measured using the specific antisera indicated above each panel. Bars represent the average of triplicate experiments.

knockdown cells, whereas in the converse experiment, the $\beta$-catenin:LEF-1 interaction was unaffected by $\alpha$-catenin knockdown (Fig. 4C). Thus, $\beta$-catenin recruits high levels of $\alpha$-catenin to Flag:LEF- 1 complexes.

The high number of recovered peptides and the intensity of the corresponding silver-stained bands indicate that $\alpha$-catenin is present in the vast majority of assembled $\beta$-catenin:LEF-1/TCF complexes. To confirm these results, we analyzed native LEF-1 complexes in Wnt3a-induced HEK293 cells. Immunoblot experiments revealed high levels of $\alpha$-catenin in the $\beta$-catenin:LEF-1/TCF complexes induced in response to Wnt3a (Fig. 4D) or Factor XV (Supplemental Fig. S4B). Further analysis showed that $\alpha$-catenin is present in both the nucleus and cytoplasm in HEK293 cells and that exposure to Wnt3a ligand (Fig. 4D) or Factor XV (Supplemental Fig. S4C) selectively increased $\beta$-catenin levels in the nucleus without affecting the level or subcellular distribution of $\alpha$-catenin (Supplemental Fig. S4D). In addition, high levels of $\alpha$-catenin were found in native LEF-1 complexes from HCT116 
colon cancer cells (Supplemental Fig. S4E), which express wild-type APC and a constitutively stable $\beta$-catenin protein. Thus, $\alpha$-catenin is an integral component of $\beta$-catenin:LEF-1/TCF complexes in Wnt3a signaling cells.

To further explore the APC complex, we also examined the composition of affinity-purified HEK293 Flag: $\alpha$-catenin complexes (Supplemental Fig. S4F). MudPIT analysis detected cell adhesion and cytoskeletal proteins, 14-3-3 proteins, $\beta$-catenin, $\gamma$-catenin, LEF-1, TCF4, CTNNBIP1/ ICAT, and APC in these fractions (Supplemental Fig. S4F). The levels of $\beta$-catenin were much higher than APC in these fractions, consistent with the observation that $\alpha$-catenin Y177 phosphorylation in HEK293 cells disrupts binding to APC. Nevertheless, endogenous APC could be readily detected in native LEF-1 complexes immunoprecipitated from Wnt3a signaling cells (Fig. 4D).

\section{$\beta$-Catenin recruits $\alpha$-catenin to Wnt target genes}

The presence of $\alpha$-catenin in the vast majority of Wnt3ainduced LEF-1 complexes indicates that it is likely to be recruited with $\beta$-catenin to endogenous Wnt target genes. This possibility was addressed with chromatin immunoprecipitation (ChIP) experiments in Wnt3a signaling HEK293 cells. Significantly, $\alpha$-catenin and $\beta$-catenin bound with similar kinetics to the $A X I N 2, D K K 1$, and SP5 gene WREs in cells incubated with Wnt3-conditioned medium (Fig. 4E). APC was also recruited to the induced genes, whereas LEF-1 was bound at the WRE before and after signaling. In addition, $\alpha$-catenin was recruited with $\beta$-catenin to the AXIN2 WRE in cells induced with Factor XV (Supplemental Fig. S4G). The ChIP signals for APC, $\alpha$-catenin, $\beta$-catenin, and LEF- 1 were detected only at the WRE and not in the downstream region. Thus, APC and $\alpha$-catenin are recruited to target gene WREs in response to Wnt3a signaling.

\section{$\alpha$-Catenin recruits APC to Wnt target genes}

The findings suggest that $\alpha$-catenin may direct APC to $\beta$-catenin:LEF-1/TCF complexes to terminate transcription at the gene and mediate the exchange of coactivator and corepressor complexes. As expected, $\alpha$-catenin knockdown in HEK293 cells induced endogenous Wnt target genes (AXIN2, DKK1, and SP5) without affecting $\beta$-catenin mRNA levels (Supplemental Fig. S5A) and increased steady-state $\beta$-catenin protein levels (Supplemental Fig. S5B). Consistent with earlier reports that $\alpha$-catenin represses Wnt/ $\beta$-catenin transactivation (Benjamin and Nelson 2008), ectopic $\alpha$-catenin also inhibited TOP-FLASH reporter activity in a dose-dependent manner (Supplemental Fig. S5C).

We next carried out a series of RNAi-ChIP experiments to examine how these factors are recruited to the AXIN2 WRE in vivo. ChIP analysis revealed that $\alpha$-catenin and $\beta$-catenin are stably bound at the AXIN2 WRE in HCT116 colon cancer cells, and $\beta$-catenin occupancy was unaffected in $\alpha$-catenin knockdown cells (Fig. 5A). In the converse experiment, the occupancy of both $\beta$-catenin and $\alpha$-catenin at the AXIN2 WRE was reduced in $\beta$-catenin knockdown cells, indicating that $\beta$-catenin recruits $\alpha$-catenin to LEF-1/TCF complexes on DNA. Moreover, depletion of either $\beta$-catenin or $\alpha$-catenin significantly decreased APC occupancy at the AXIN2 WRE (Fig. 5A), indicating that $\alpha$-catenin recruits APC to the $\beta$-catenin:LEF-1 complex in vivo. Identical results were obtained at the $c-M Y C$ gene in HCT116 cells (Supplemental Fig. S5D,E). Importantly, depletion of $\alpha$-catenin, APC, or LSD1 strongly increased anchorage-independent cell growth in soft agar colony growth experiments (Supplemental Fig. S5F), indicating that each of these factors inhibits endogenous Wnt signaling in HCT116 cells.

The regulation of Wnt target genes was also examined in $\alpha$-catenin-null PC3 metastatic prostate cancer cells. Re-expression of $\alpha$-catenin in these cells (PC3- $\alpha$-catenin) strongly enhances cell adhesion and inhibits cell growth (Inge et al. 2008). Quantitative RT-PCR (qRT-PCR) experiments confirmed widespread repression of Wnt target genes (AXIN2, KLK3, cMYC, HMG1, DKK1, and $C C N D 1)$ in PC3- $\alpha$-catenin cells compared with control PC3 cells (Fig. 5B), whereas $\beta$-CATENIN, E2F1, and $M A M L 2$ mRNA levels were unaffected. ChIP experiments revealed that $\alpha$-catenin restored binding of APC and LSD1 to the AXIN2 WRE, accompanied by a loss of H3K4me3 and reduced $\beta$-catenin occupancy (Fig. 5C). Identical results were obtained at the $c M Y C$ WRE in PC3$\alpha$-catenin cells (Supplemental Fig. S5G). The re-expressed $\alpha$-catenin reduced nuclear $\beta$-catenin protein levels without affecting mRNA levels (Supplemental Fig. $\mathrm{S} 5 \mathrm{H})$. Furthermore, knockdown of LSD1 up-regulated AXIN2 mRNA levels in Wnt3a signaling HEK293 cells (Supplemental Fig. S5I, left panel). ChIP analysis revealed that LSD1 occupancy increased at the AXIN2 WRE in response to Wnt3a signaling, and knockdown of LSD1 decreased H3K4me2/3 levels at the gene (Supplemental Fig. S5I, right panel). Thus, $\alpha$-catenin recruits APC and LSD1 to switch off transcription at the AXIN2 gene.

To define the domain of APC responsible for targeting to the WRE, wild-type and mutant Flag:APC proteins were ectopically expressed in DLD1 colon cancer cells and examined by ChIP for binding to the endogenous AXIN2 WRE. DLD1 cells contain biallelic APC truncations that both express APC mutant proteins that lack the CID and constitutively activate Wnt target genes. ChIP analysis revealed that $\beta$-catenin, $\alpha$-catenin, and LEF-1 are stably bound to the AXIN2 WRE in these cells (Supplemental Fig. S5J). As observed previously (Sierra et al. 2006), newly expressed Flag:APC rapidly binds to the AXIN2 WRE and could be readily detected by ChIP using an anti-Flag antibody. Interestingly, the Flag:APC (amino acids 1-1551) mutant, which retains the CID and can repress Wnt/ $\beta$-catenin transactivation (Supplemental Fig. S5K), was efficiently targeted to the AXIN2 WRE. In contrast, the shorter Flag:APC (amino acids 1-832) mutant, which lacks the CID and cannot inhibit $\beta$-catenin activity (Supplemental Fig. S5K), did not bind to the AXIN2 gene (Supplemental Fig. S5J). Thus, $\alpha$-catenin and the CID are both required for targeting of APC to the AXIN2 WRE in vivo. 
A

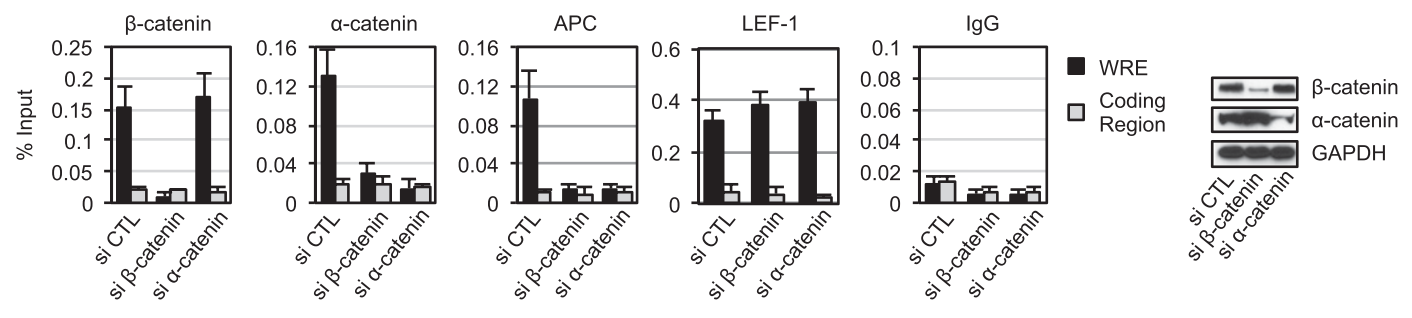

B
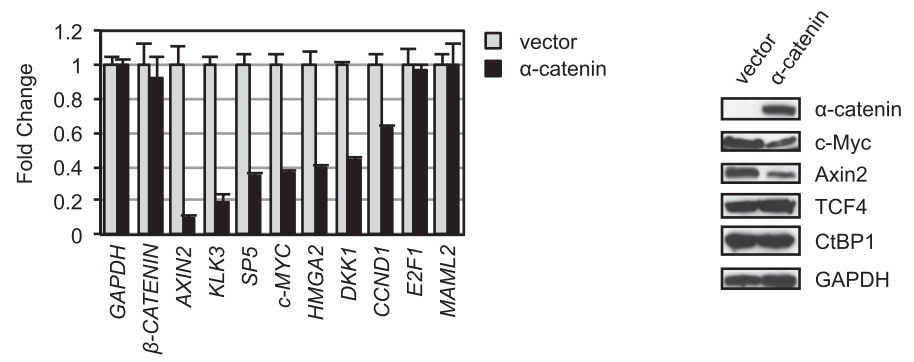

C
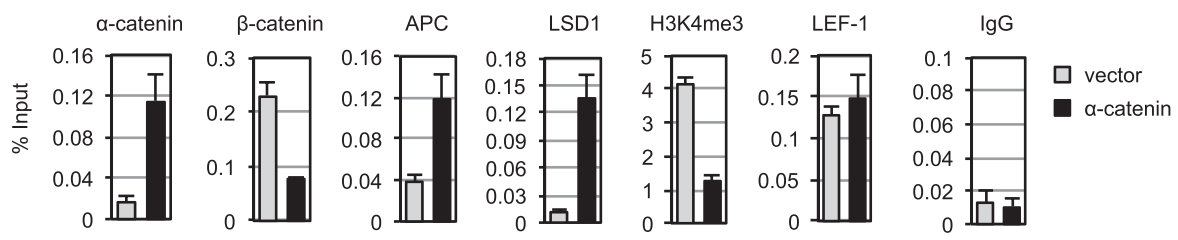

Figure 5. RNAi-ChIP analysis of $\alpha$-catenin-mediated repression of Wnt target genes. (A) RNAi-ChIP analysis of the AXIN2 WRE (black) and coding region (gray) in HCT116 cells treated with control-specific (si CTL), $\beta$-catenin-specific, or $\alpha$-catenin-specific siRNAs. Chromatin was immunoprecipitated with the antisera indicated above each panel. (Bottom right panel) The knockdown efficiency was measured by immunoblot. (B) qRT-PCR analysis of endogenous Wnt target gene mRNA levels in stable PC-3 cell lines expressing an empty vector (gray) or $\alpha$-catenin (black). Each bar represents the average of three independent experiments. (Right panel) Expression of $\alpha$-catenin and $\beta$-catenin was examined by immunoblot. $(C)$ ChIP analysis at the AXIN2 WRE in control PC-3 (gray) and $\alpha$-cateninexpressing (black) PC3 cells using the antisera indicated above each panel.

\section{APC and $\alpha$-catenin regulate $\beta$-catenin turnover at Wnt target genes}

We next examined whether $\alpha$-catenin, like APC, affects the kinetics of $\beta$-catenin release from AXIN2 following the withdrawal of Factor XV. ChIP experiments revealed high levels of RNA polymerase II (RNAPII) Ser5P at the AXIN2 gene promoter in HEK293 cells prior to $\beta$-catenin induction (Supplemental Fig. S6A), indicating the presence of paused or inefficiently elongating RNAPII complexes. Gene activation was accompanied by a strong increase in RNAPII Ser2P levels at the promoter and in the AXIN2 coding region. Withdrawal of Factor XV resulted in a rapid loss of $\beta$-catenin and phosphorylated RNAPII, whereas LEF-1 remained bound to the WRE. Moreover, $\alpha$-catenin and APC were recruited to the gene upon signaling and rapidly released upon Factor XV withdrawal.

Remarkably, knockdown of $\alpha$-catenin strongly delayed the release of $\beta$-catenin from the AXIN2 gene upon Factor $\mathrm{XV}$ withdrawal (Fig. 6A). Moreover, histone H2Bub, H3K4me3, and RNAPII Ser2P elongation complex levels remained high in these cells despite withdrawal of the inducer. The extended occupancy of $\beta$-catenin and associated coactivators at the AXIN2 WRE is consistent with the loss of ubiquitylation and increased $\beta$-catenin protein stability seen in $\alpha$-catenin knockdown cells (Fig. 2A-C).

We also noted that Factor XV withdrawal induced the rapid release of $\alpha$-catenin and $\beta$-catenin from Flag:LEF-1 complexes in co-IP experiments (Supplemental Fig. S6B). Treatment of these cells with MG132 prevented the release of $\alpha$-catenin and $\beta$-catenin from the Flag:LEF-1 beads, accompanied by increased $\beta$-catenin S33 phosphorylation and presumptive ubiquitylation, as visualized by immunoblot of HA-Ub-labeled proteins (Fig. 6B). High levels of ubiquitylated $\beta$-catenin in these fractions were confirmed by $\beta$-catenin immunoblot of anti-Ub immunoprecipitates (Fig. 6C). Thus, the APC destruction complex might regulate disassembly of the $\alpha$-catenin: $\beta$-catenin:LEF-1 complex. Consistent with this possibility, knockdown of either APC or $\beta \operatorname{TrCP} 1$ prevents the dissociation of $\beta$-catenin:Flag:LEF-1 complexes (Fig. 6D) compared with cells treated with a control siRNA. Most importantly, identical results were obtained in cells depleted of $\alpha$-catenin (Fig. 6E). Thus, $\alpha$-catenin acts with APC and $\beta$ TrCP1 to regulate $\beta$-catenin:LEF-1 complex 
Choi et al.
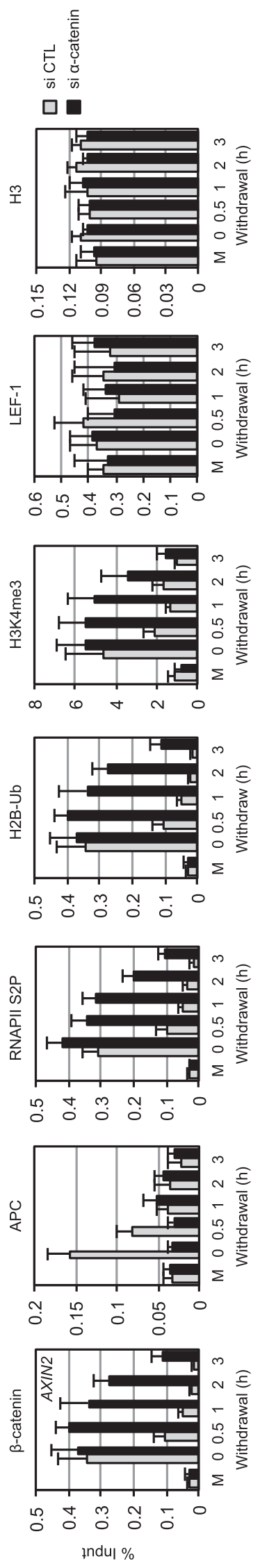

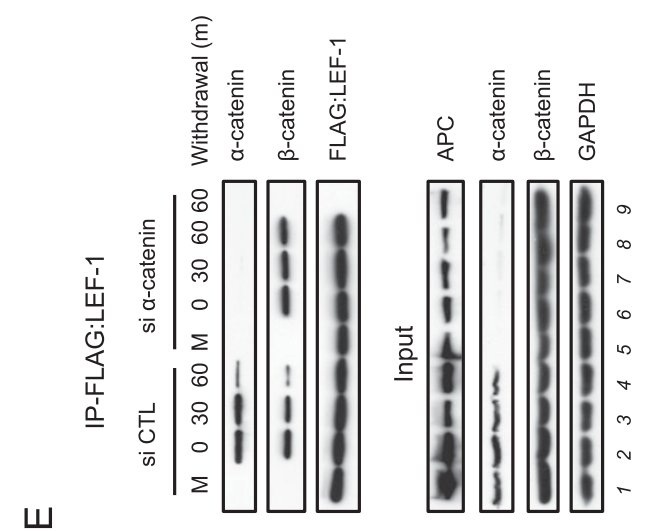

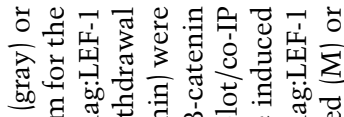

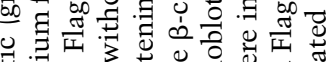

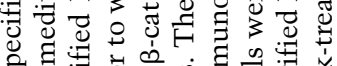

की

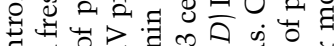

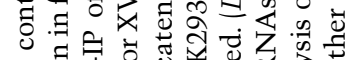

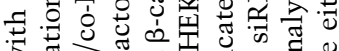
उ 한 ए

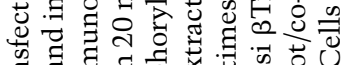

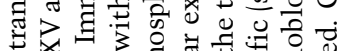

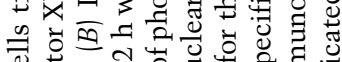
उ

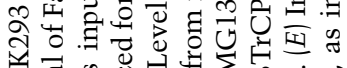

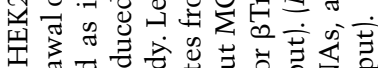

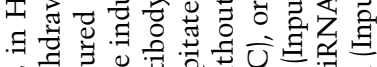

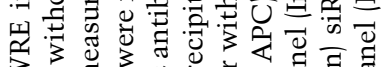

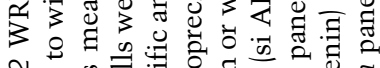

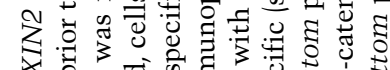

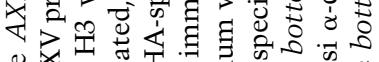

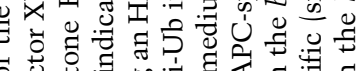
○

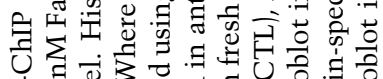

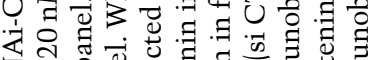

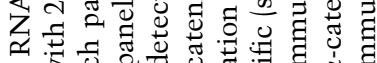

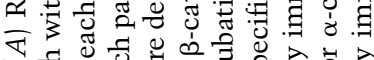

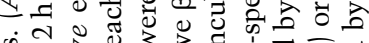

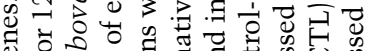

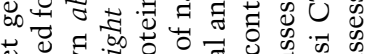

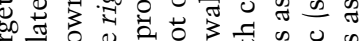

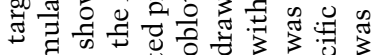

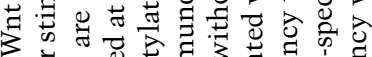
उ

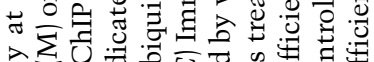

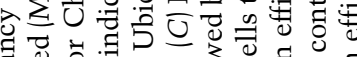

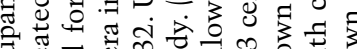
ज्ञ

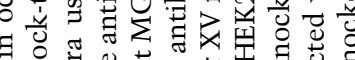

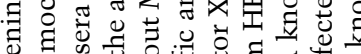

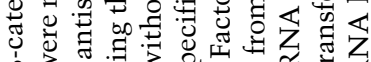

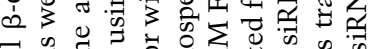

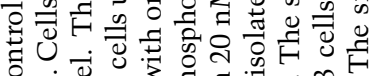
ठै.

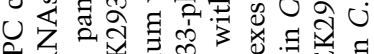
य क्जि 寻艺

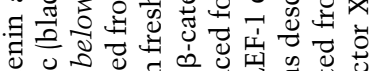

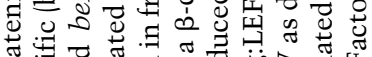
U.

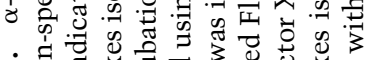



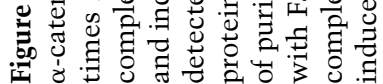


levels in the soluble fraction and on chromatin at the AXIN2 WRE.

\section{Knockdown of $\alpha$-catenin prolongs Wnt signaling and promotes hESC endodermal differentiation}

Cell adhesion complexes are often disrupted in transformed cells, leading $\alpha$-catenin and $\beta$-catenin to accumulate in the cytoplasm and nucleus to levels significantly higher than seen in primary cells. Consequently, we asked whether $\alpha$-catenin and APC are also present at Wnt enhancer complexes in hESCs, which are induced to differentiate to mesodermal and endodermal cell fates in response to Wnt3a ligand or GSK3 $\beta$ inhibitors (Wray and Hartmann 2012). As shown in Figure 7A, treatment of H1
hESCs with either Wnt3a ligand or Factor XV strongly induced canonical Wnt target genes (AXIN2 and SP5) followed by a delayed activation of endodermal marker genes (CRCX4, SOX17, and FOXA2) at $48 \mathrm{~h}$. Subcellular fractionation analysis revealed that $\beta$-catenin and $\alpha$-catenin localize predominantly to the cytoplasm and cell membrane in these cells, whereas LEF-1 is nuclear, and APC distributes in both cytoplasmic and nuclear fractions (Supplemental Fig. S7A). Unlike the situation in transformed cells, $\beta$-catenin and $\alpha$-catenin levels are low in the nucleus and scarcely increase following $4 \mathrm{~h}$ of incubation with Factor XV (Supplemental Fig. S7A), suggesting that functional destruction complexes are more limiting in hESCs. However, $\beta$-catenin levels clearly increased at longer time intervals at $48 \mathrm{~h}$ and $72 \mathrm{~h}$
A
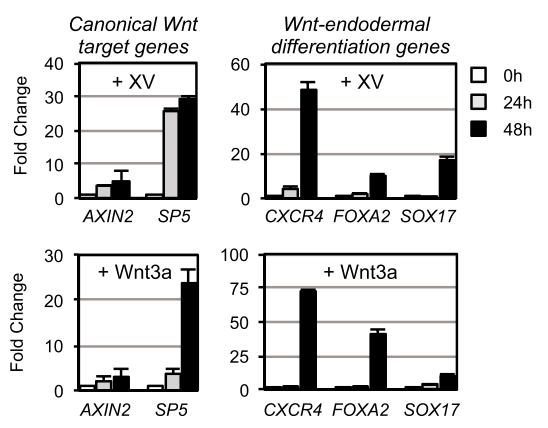

C

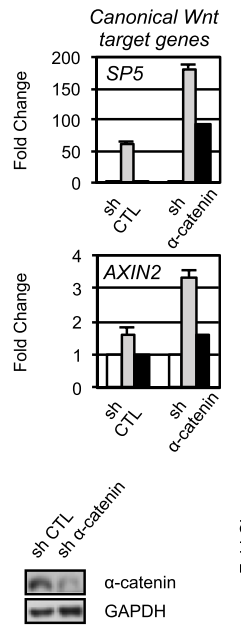

B
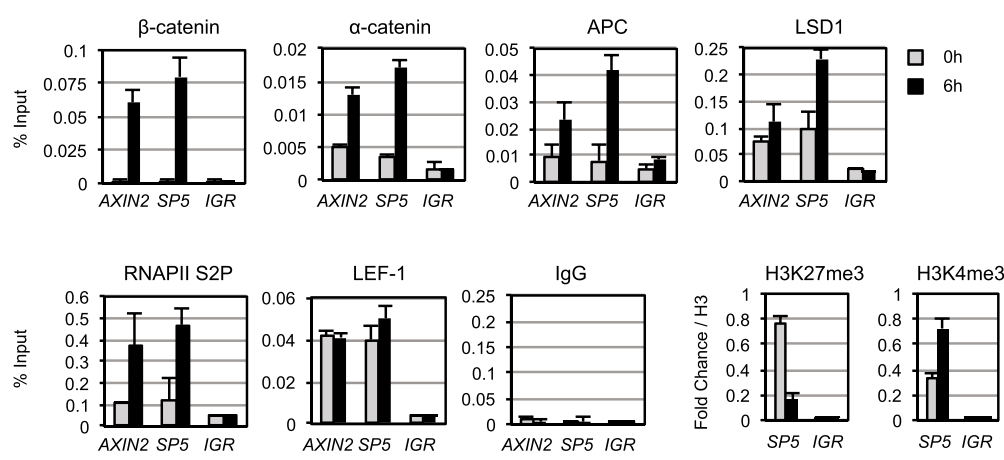



D

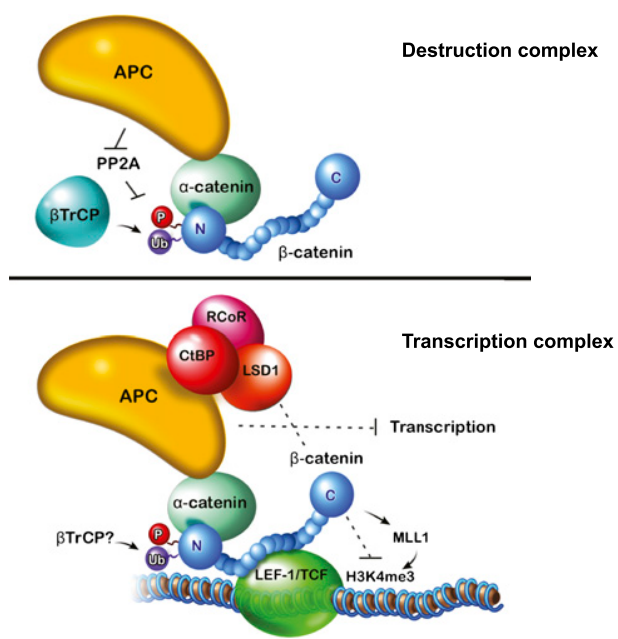

Figure 7. $\alpha$-Catenin inhibits Wnt/ $\beta$-catenin-induced transcription and hESC differentiation. (A) Time-course qRT-PCR analysis of canonical Wnt target genes and endodermal differentiation marker genes in hESCs treated with $50 \mathrm{nM}$ Factor XV (top panel) or recombinant Wnt3a (bottom panel). mRNA levels were normalized to GAPDH. (B) ChIP analysis of the AXIN2 and SP5 genes in hESCs in mock-treated cells (uninduced, gray) or cells treated with $50 \mathrm{nM}$ Factor XV for $6 \mathrm{~h}$ (black). The antisera used for ChIP are indicated above each panel. H3K27me3 and H3K4me3 levels at the SP5 gene were normalized to total histone H3. (C) qRT-PCR analysis of canonical Wnt target genes and endodermal differentiation marker genes. mRNA levels were measured in stable hESC lines expressing control-specific or $\alpha$-catenin-specific shRNAs. Cells were treated with Factor XV for $24 \mathrm{~h}$ (gray) followed by withdrawal and incubation with fresh medium for an additional $24 \mathrm{~h}$ (black). The schematic at the right illustrates how cells treated with $\alpha$-catenin shRNA but not control shRNA fail to terminate Wnt-induced transcription of endodermal differentiation genes, and $\beta$-catenin signaling progresses to activate the endoderm differentiation pathway. $(D)$ Summary and model for the role of $\alpha$-catenin in the APC destruction complex (shown in the top panel) and in recruiting the APC complex to $\beta$-catenin:LEF-1 complexes at Wnt target genes. See the text for details. 
following induction, especially in the nuclear fraction (Supplemental Fig. S7B). Thus, functional APC complexes appear to be limiting at early times in induced hESCs but are sufficient to enable the rapid induction of Wnt target genes.

ChIP analysis at the AXIN2 and SP5 genes confirmed that $\beta$-catenin was recruited rapidly upon Factor $\mathrm{XV}$ induction of hESCs, and gene activation was accompanied by increased levels of RNAPII Ser2P and H3K4me3 and loss of H3K27me3 (Fig. 7B). APC and LSD1 were also recruited with $\beta$-catenin to the AXIN2 WRE in hESCs. This binding was specific to LEF-1 at the WRE and was not observed in a control intergenic region. To examine the role of the APC destruction complex in the turnover of $\beta$-catenin at the target gene, stable hESCs were derived expressing APC or $\alpha$-catenin shRNAs (Supplemental Fig. $\mathrm{S} 7 \mathrm{C}$ ). Wnt target gene mRNA levels remained elevated in stable $\alpha$-catenin knockdown or APC knockdown hESCs following withdrawal of Factor XV (Fig. S7D), consistent with the high levels of $\beta$-catenin and RNAPII Ser2P observed at the AXIN2 gene in APC-depleted hESCs (Supplemental Fig. S7E). Importantly, $\alpha$-catenin knockdown cells also induced Wnt differentiation gene (SOX17, CXCR4, and FOXA2) expression following transient activation of $\beta$-catenin, unlike cells expressing a control shRNA (Fig. 7C). In this experiment, induction of $\beta$-catenin was terminated after $24 \mathrm{~h}$ by removal of Factor XV. In control cells, none of the Wnt endodermal differentiation genes were activated. However, in cells depleted of $\alpha$-catenin, Wnt target genes fail to switch off, and the differentiation genes are strongly induced. Similar effects were also observed in hESCs depleted of Axin, consistent with a role for $\alpha$-catenin in the destruction complex (Supplemental Fig. S7F). Importantly, $\alpha$-catenin depletion was unable to activate target genes in the absence of Factor $\mathrm{XV}$, indicating that the effect is specific for Wnt/ $\beta$-catenin-induced transcription (Fig. 7C, $0 \mathrm{~h}$ ). We conclude that $\alpha$-catenin is required to switch off Wnt target gene expression and prevent $\beta$-catenin-induced differentiation in hESCs. In summary, the findings reported here indicate that $\alpha$-catenin interacts with the APC CID and facilitates $\beta$-catenin proteolysis through stabilizing the destruction complex and promoting ubiquitylation. In addition, we found that $\alpha$-catenin directs the APC complex to WREs to control H3K4 methylation and the exchange of coregulator complexes (Fig. 7D).

\section{Discussion}

In this study, we demonstrate that $\alpha$-catenin interacts with the APC tumor suppressor to repress Wnt target gene expression and facilitate proteolysis of the $\beta$-catenin transcriptional activator. This interaction is mediated through the APC CID, a mutation hot spot for APC in colon cancers that is essential for the destruction of $\beta$-catenin. The association of $\alpha$-catenin with APC is independent of $\beta$-catenin, and APC and $\beta$-catenin bind to distinct but adjacent sites at the $\mathrm{N}$ terminus of $\alpha$-catenin. Most importantly, $\alpha$-catenin promotes $\beta$-catenin ubiquitylation and proteolysis by both stabilizing the association of $\beta$-catenin with the APC destruction complex and preserving the phosphodegron. Using MudPIT proteomics analysis of Wnt regulatory complexes, we discovered that $\alpha$-catenin accompanies $\beta$-catenin to LEF-1/TCF complexes at target genes in Wnt3a signaling cells and recruits APC in a large complex containing CtBP:RCOR1: LSD1. We previously showed that full-length APC rapidly localizes to the WREs of target genes when re-expressed in HT29 colon cancer cells and functions to switch off transcription and recruit the Gro/TLE corepressor (Sierra et al. 2006). The current findings show that $\alpha$-catenin targets APC to the $\beta$-catenin:LEF-1 WRE complex (Fig. 7D). Knockdown of either $\alpha$-catenin or APC prevents the release of $\beta$-catenin from LEF-1 complexes upon termination of signaling and strongly prolongs $\beta$-catenin occupancy at the WRE. Last, we found that APC and $\alpha$-catenin are also recruited to Wnt target genes in signaling hESCs. Failure to switch off Wnt target genes upon knockdown of $\alpha$-catenin in hESCs potently up-regulates endodermal differentiation genes. Thus, $\alpha$-catenin acts through APC to control both $\beta$-catenin stability and activity at Wnt target genes.

\section{A role for $\alpha$-catenin in the APC destruction complex}

Several observations support the idea that $\alpha$-catenin has an important functional role within the APC destruction complex. First, $\beta$-catenin ubiquitylation and proteolysis were strongly inhibited by point mutations (T120 and Y142) that prevent binding to $\alpha$-catenin as well as by siRNA-mediated knockdown of $\alpha$-catenin. Second, $\alpha$-catenin was required to preserve the $\beta$-catenin phosphodegron and association with $\beta$ TrCP1. These results support earlier observations that full-length APC, but not cancer-associated mutants, protects the $\beta$-catenin phosphodegron from the PP2A phosphatase (Su et al. 2008) and that APC regulation of $\beta$-catenin phosphorylation occurs within a complex that includes $\alpha$-catenin (Layton et al. 2012). Third, we showed that $\alpha$-catenin recognizes the APC CID and selectively stabilizes binding of $\beta$-catenin to the native APC complex. It remains to be determined whether the $\alpha$-catenin: APC interaction is direct or mediated through additional factors. Although ectopically expressed $\beta$-catenin can recognize the APC $3 \times 15 R$, this domain is not required for proteolysis by the full-length APC protein (Kohler et al. 2009; Roberts et al. 2011). Moreover, the 3x15R domain interacts strongly with the CtBP:RCOR1:LSD1 complex, which might block the access of $\beta$-catenin to this site in the native complex. Instead, we found that $\alpha$-catenin helps tether $\beta$-catenin to APC both within the destruction complex and at LEF-1/TCF complexes bound to the WRE. Recent studies indicate that $\beta$-catenin is degraded within a large cytoplasmic Axin1-proteasome complex (Li et al. 2012), and $\alpha$-catenin may have additional contacts and functions within this destruction complex.

Global phosphoproteome studies indicate that the APC-binding site in $\alpha$-catenin is frequently tyrosinephosphorylated at Y177 in transformed cells (http://www. phosphosite.org). We show that $\alpha$-catenin Y177 phosphorylation selectively disrupts binding to APC but not $\beta$-catenin 
and that point mutation of this site (Y177F) blocks phosphorylation and strongly potentiates binding to APC and repression of Wnt target genes. Conversely, the Q176A mutation both reduces binding of $\alpha$-catenin to APC and disrupts its ability to repress transcription and cell growth. Tyrosine phosphorylation of $\beta$-catenin was previously suggested to inhibit binding to both E-cadherin and $\alpha$-catenin in cancer cells (Ji et al. 2009). Thus, tyrosine kinases may act through multiple mechanisms to increase $\beta$-catenin levels in the nucleus and disrupt Wnt target gene repression. At later stages of cancer progression, $\alpha$-catenin is frequently deleted or repressed by promoter methylation (which would fully stabilize $\beta$-catenin and constitutively activate Wnt target genes) coordinately with a loss in cell adhesion and increased metastasis. It will be important to identify the tyrosine kinase responsible for $\alpha$-catenin Y177 phosphorylation because inhibiting this step might help counteract oncogenic $\beta$-catenin activity in EGFR-positive and other cancers that express wild-type APC.

\section{A role for $\alpha$-catenin and APC in the $\beta$-catenin:LEF-1/ TCF complex at Wht target genes}

Our findings also have interesting implications for the role of $\alpha$-catenin in the Hippo kinase cascade, which controls organ cell growth, apoptosis, and cell contact inhibition through down-regulation of Wnt, GPCR, and other signaling pathways (Tsai et al. 2012; Yu et al. 2012; $\mathrm{Yu}$ and Guan 2013). The presence of $\alpha$-catenin in the $\beta$-catenin:LEF-1 complex at the WRE (Fig. 7D) suggests that the transcription complex is arranged similarly to the cell adhesion complex, with the exception that $\beta$-catenin is bound to LEF-1/TCF rather than E-cadherin. APC can also influence cell adhesion through association with cell adherens junctions (Hamada and Bienz 2004). Consequently, it will be important to assess whether $\alpha$-catenin Y177 phosphorylation disrupts the association of APC with the cell membrane and weakens cell adhesion coordinately with the loss of repression at Wnt target genes. More broadly, cell density may control transcription through changes in $\alpha$-catenin Y177 phosphorylation or the subcellular localization and activity of the CtBP:RCOR1:LSD1 and $\alpha$-catenin:APC complexes. We showed previously that the activity of APC at the gene preceded by several hours the decline in $\beta$-catenin protein levels (Sierra et al. 2006), indicating that it acts directly to switch off transcription. Alternatively, the effects of $\alpha$-catenin and APC knockdown on $\beta$-catenin occupancy could reflect a thermodynamic equilibrium of $\beta$-catenin levels established by its destruction in the cytoplasm. Because APC binds phosphorylated $\beta$-catenin, it will be important to assess whether this modification is preserved in LEF-1 complexes and at the WRE and whether $\beta$ TrCP-mediated ubiquitylation might also occur at the gene, consistent with the extensive role of the UB-proteasome system in regulated transcription (Geng et al. 2012).

APC interacts directly with CtBP (Hamada and Bienz 2004), and our studies suggest it is also a scaffold for the larger complex that includes RCOR1 and LSD1. CtBP protein levels are up-regulated in early adenomas from FAP patients, indicating that it is also an important substrate for the APC destruction complex (Phelps et al. 2009; Rai et al. 2010). CtBP is a potent repressor of many tumor suppressors (Chinnadurai 2009) and inhibits production of retinol dehydrogenases and retinoic acid biosynthesis to disrupt intestinal differentiation in early stage adenomas (Phelps et al. 2009; Rai et al. 2010). However, CtBP has a complex role in the expression of Wnt target genes, as it functions to both repress basal gene expression and enhance $\beta$-catenin transactivation (Fang et al. 2006). This raises the possibility that some subunits of the APC complex are also needed to switch on Wnt target genes. Interestingly, ubiquitylation of CtBP by the TBL1/TBLR1 complex regulates cofactor exchange at nuclear receptor genes (Perissi et al. 2008). The TBL1/ TBLR1 proteins also control $\beta$-catenin occupancy at Wnt target genes (Li and Wang 2008), and it will be of interest to learn whether APC is involved in this step. Other APC destruction complex substrates are the YAP1 homolog TAZ (Azzolin et al. 2012) and Ras (Jeong et al. 2012). The failure of APC mutants to degrade CtBP, TAZ, and Ras further suggests that $\alpha$-catenin may regulate the destruction of these other substrates and might explain why ablation of $\alpha$-catenin elevates Ras-MAPK kinase activity in murine intestinal epithelial cells (Vasioukhin et al. 2001).

Mechanistic studies have shown that $\alpha$-catenin represses transcription by sequestering the YAP1/TAZ transcriptional coactivator in inactive complexes in the cytoplasm (Robinson and Moberg 2011; Schlegelmilch et al. 2011; Silvis et al. 2011; Imajo et al. 2012; Rosenbluh et al. 2012). Our data indicate that $\alpha$-catenin could potentially regulate TAZ activity directly at Wnt target genes or escort it to the cytoplasm for destruction by the APC complex. Because $\alpha$-catenin and APC are recruited with $\beta$-catenin to target genes, their transcriptional activities must be regulated to prevent premature termination of transcription. One interesting possibility is that Y177 phosphorylation of $\alpha$-catenin might prevent docking of APC prior to activation of the RNAPII elongation complex. Analysis of transcription-coupled turnover of TGF $\beta$ signaling established a role for $\mathrm{P}-\mathrm{TEFb} / \mathrm{CDK} 9$ and CDK8 phosphorylation of SMAD3 in the recruitment of YAP1 and release of the coactivator complex from the DNA (Alarcón et al. 2009; Aragon et al. 2011). Assembly of active RNAPII elongation complexes could similarly trigger the release and nuclear export of $\beta$-catenin by the $\alpha$-catenin:APC complex. Given that nuclear actin proteins play a critical role in gene expression (Gieni and Hendzel 2009), the ability of $\alpha$-catenin and APC to regulate actin and associated proteins (Aoki and Taketo 2007; McCartney and Näthke 2008), including the Arp2/3 complex (Benjamin and Nelson 2008; Benjamin et al. 2008), may also play an important role in the transcriptional activity of the APC complex.

At target genes, $\beta$-catenin interacts with several proteins that regulate $\mathrm{H} 3 \mathrm{~K} 4$ methylation. The $\mathrm{N}$ terminus of $\beta$-catenin targets BCL9/Legless and the Pygopus PHD 
finger protein coactivator, which binds H3K4me2 and stimulates H3K4me3 (Fiedler et al. 2008), and the C-terminal activation domain associates with the MLL1:Menin complex, which mediates H3K4me3 (Sierra et al. 2006). The N terminus of $\beta$-catenin also binds $\alpha$-catenin, which recruits APC complexes bound to the CtBP:RCOR1 corepressors and LSD1 H3K4me1/2 demethylase. Thus, the $\alpha$-catenin:APC:CtBP:LSD1 and Bcl9:Pygopus complexes bind to adjacent sites on $\beta$-catenin and might compete for binding to $\mathrm{H} 3 \mathrm{~K} 4 \mathrm{me} 2$ to switch transcription between on and off states. Interestingly, MLL1 and H3K4me3 also regulate coactivator:corepressor exchange at the HOXA9 gene, and this step is permanently disabled in leukemogenic MLL1 translocation proteins (Wang et al. 2010). Thus, the H3K4 methylation step is disrupted in distinct ways to ensure constitutive oncogene expression in leukemic and colon cancer cells.

Last, we show that $\alpha$-catenin is a strong inhibitor of $\beta$-catenin transactivation in hESCs, which respond to Wnt signaling through differentiation to endodermal and mesodermal cell fates (Wray and Hartmann 2012). Despite low levels of $\alpha$-catenin and $\beta$-catenin in the nuclear and cytoplasmic compartments of these cells, Wnt target genes are induced rapidly in response to Wnt3a or GSK3 $\beta$ inhibitors, and we found that $\alpha$-catenin, APC, and LSD1 accompany $\beta$-catenin to induced genes. Following transient induction of $\beta$-catenin, Wnt target genes fail to shut off in cells depleted of $\alpha$-catenin, which strongly upregulates downstream endodermal genes and promotes hESC differentiation. In contrast, lentiviral shRNA knockdown of $\alpha$-catenin was not sufficient to induce Wnt target genes in nonsignaling cells, consistent with the observation that conditional knockout of $\alpha$-catenin in murine epithelial cells also fails to activate the pathway (Vasioukhin et al. 2001). Consequently, this system will be useful to analyze the mechanisms regulating Wnt signaling and endodermal differentiation.

In summary, the interaction of $\alpha$-catenin with APC plays an important role in $\beta$-catenin ubiquitylation and proteolysis and turnover of $\beta$-catenin at Wnt target genes and is disrupted by $\alpha$-catenin Y177 phosphorylation, which prevents repression of Wnt target genes in transformed cells. Binding to APC might also affect $\alpha$-cateninmediated cell adhesion and rearrangement of the actin cytoskeleton, contributing to the misregulation of each of these processes in cancer.

\section{Materials and methods}

\section{Cell culture and DNA transfection}

HEK293 and HCT116 cells were cultured in DMEM supplemented with $2 \mathrm{mM}$ L-glutamine and $10 \%$ fetal bovine serum in a $\mathrm{CO}_{2}(5 \%)$ incubator at $37^{\circ} \mathrm{C}$. PC-3 cells were cultured in RPMI1640 with $2 \mathrm{mM}$ L-glutamine and $10 \%$ fetal bovine serum. G418 selection was carried out by addition of G418 at final concentration of $500 \mu \mathrm{g} / \mathrm{mL}$. For ectopic expression of vector DNA, $4 \mu \mathrm{g}$ of DNA was transfected into HEK293 cells using LipoD293TM DNA in vitro transfection reagent (SignaGen Laboratories) following instructions from the supplier. TOPFLASH reporter assays, cell fractionation, immunoprecipitation, and immunoblot procedures are described in the Supplemental Material.

\section{SiRNA transfection}

siRNAs were obtained from Life Technologies. siRNA transfection was performed with Lipofectamine RNAiMAX transfection reagent by following instructions from the supplier. Assays were performed $48 \mathrm{~h}$ after transfection. For negative control siRNA, Silencer negative control \#1 siRNA was used (Life Technologies). Specific siRNA sequences used are available on request.

\section{Reverse transcription and $q R T-P C R$}

Total RNA was isolated using Trizol reagent (Life Technologies), and reverse transcription was performed with $3 \mu \mathrm{g}$ of extracted RNA using SuperScript III (Life Technologies) with oligo-dT according to the manufacturer's instructions. PCR measurements to cDNA were performed in triplicate using SYBR Green master mixes (Life Technologies). Amplification was carried out in the ABI7300 (Applied Biosystems) with a 10-min DNA denaturation step at $95^{\circ} \mathrm{C}$, followed by 40 cycles of $15 \mathrm{sec}$ at $95^{\circ} \mathrm{C}$ and $60 \mathrm{sec}$ at $60^{\circ} \mathrm{C}$. The average of the technical replicates was normalized to GAPDH levels using the comparative CT method. Averages and standard deviations of at least three experiments are shown in the figures. The qRT-PCR primers are listed in the Supplemental Material.

\section{Affinity purification of Flag-tagged protein complexes and MudPIT analysis}

Stable expression of Flag-tagged full-length human $\beta$-catenin, TCF4, LEF-1, $\alpha$-catenin, and APC (amino acids 1-2227) in HEK293 cells was established using G418 selection. Cells from 15 150-mm dishes were extracted using immunoprecipitation buffer $(50 \mathrm{mM}$ HEPES-NaOH at $\mathrm{pH} 7.9,300 \mathrm{mM} \mathrm{NaCl}, 1 \%$ $\mathrm{NP}-40,10 \mathrm{mM} \mathrm{MgCl}_{2}, 15 \%$ glycerol) with protease inhibitors to a final volume of $15 \mathrm{~mL}$ and homogenized for nuclear extraction after cytosolic bust. Extracts were clarified by centrifugation $\left(14,000 \mathrm{~g}\right.$ for $15 \mathrm{~min}$ at $\left.4^{\circ} \mathrm{C}\right)$. Flag-M2 beads (Sigma) were incubated with the supernatant in a ratio of $80 \mu \mathrm{L}$ of slurry $150 \%$ beads in slurry) to $6 \mathrm{mg}$ of total protein for $4 \mathrm{~h}$ on a roller at $4^{\circ} \mathrm{C}$. The beads were washed in immunoprecipitation wash buffer ( 25 mM HEPES- $\mathrm{NaOH}$ at $\mathrm{pH} 7.9,300 \mathrm{mM} \mathrm{NaCl}, 0.2 \% \mathrm{NP}-40$ ) four times for $3 \mathrm{~min}$ at $4^{\circ} \mathrm{C}$ and then twice in Flag-elution buffer $(25$ $\mathrm{mM}$ Tris- $\mathrm{HCl}$ at $\mathrm{pH} 7.5,50 \mathrm{mM} \mathrm{NaCl}$ ). Finally, the sample was incubated with $200 \mu \mathrm{g} / \mathrm{mL}$ Flag peptide (Sigma) in elution buffer for $30 \mathrm{~min}$ at room temperature with rotation. The MudPIT protein identification methods and analysis are detailed in the Supplemental Material. Original data files will be made available at http://www.yeastrc.org within 1 year of publication.

\section{ChIP experiments}

The procedure, primers, and antisera used for the ChIP studies are described in the Supplemental Material.

\section{Maintenance of hESCs}

H1 hESCs were cultured in mTeSR1 on Matrigel-coated (BD Biosciences) tissue culture plates. Cultures were passaged manually as clumps at 1:3 split ratio every $5-7 \mathrm{~d}$ following treatment with $1 \mathrm{mg} / \mathrm{mL}$ dispase. Medium was replaced daily. For experiments, clumps were disaggregated into single cells at 1:6 split 
ratio using Accutase. Mouse recombinant Wnt3a or GSK3 inhibitor Factor XV (Millipore) was added to the mTeSR1 medium at a final concentration of $100 \mathrm{ng} / \mathrm{mL}$ and $50 \mathrm{nM}$, respectively.

\section{Acknowledgments}

We thank W. Travis Berggren for assistance with ESC culture, Patricia G. Tu for assistance with MudPIT proteomics, and the members of the Jones laboratory for helpful discussions. This work was supported by The Jean Hahn Hardy and Salk Alumni Fellowship Awards (to S.H.C.), The Pioneer Fund Scholar Award (to C.E.), NIH/NIGMS P41 GM103533 (to J.R.Y.), and NIH/NCI RO1CA125535 (to K.A.J.).

\section{References}

Alarcón C, Zaromytidou AI, Xi Q, Gao S, Yu J, Fujisawa S, Barlas A, Miller AN, Manova-Todorova K, Macias MJ, et al. 2009. Nuclear CDKs drive Smad transcriptional activation and turnover in BMP and TGF- $\beta$ pathways. Cell 139: 757-769.

Aoki K, Taketo MM. 2007. Adenomatous polyposis coli (APC): A multi-functional tumor suppressor gene. I Cell Sci 120: 3327-3335.

Aragon E, Goerner N, Zaromytidou AI, Xi Q, Escobedo A, Massague J, Macias MJ. 2011. A Smad action turnover switch operated by WW domain readers of a phosphoserine code. Genes Dev 25: 1275-1288.

Atilla-Gokcumen GE, Williams DS, Bregman H, Pagano N, Meggers E. 2006. Organometallic compounds with biological activity: A very selective and highly potent cellular inhibitor for glycogen synthase kinase 3. ChemBioChem 7: 1443-1450.

Azzolin L, Zanconato F, Bresolin S, Forcato M, Basso G, Bicciato S, Cordenonsi M, Piccolo S. 2012. Role of TAZ as mediator of Wnt signaling. Cell 151: 1443-1456.

Benjamin JM, Nelson WJ. 2008. Bench to bedside and back again: Molecular mechanisms of $\alpha$-catenin function and roles in tumorigenesis. Semin Cancer Biol 18: 53-64.

Benjamin JM, Kwiatkowski AV, Yang C, Korobova F, Pokutta S, Svitkina T, Weis WI, Nelson WJ. 2008. $\alpha$ E-catenin regulates actin dynamics independently of cadherin-mediated cell-cell adhesion. J Cell Biol 189: 339-352.

Caldwell CM, Kaplan KB. 2009. The role of APC in mitosis and chromosome instability. Adv Exp Med Biol 656: 51-64.

Chinnadurai G. 2009. The transcriptional corepressor CtBP: A foe of tumor suppressors. Cancer Res 69: 731-734.

Clevers H, Nusse R. 2012. Wnt/ $\beta$-catenin signaling and disease. Cell 149: 1192-1205.

Fang M, Li J, Blauwkamp T, Bhambhani C, Campbell N, Cadigan KM. 2006. C-terminal binding protein directly activates and represses Wnt transcriptional targets in Drosophila. EMBO I 25: 2735-2745.

Fiedler M, Sánchez-Barrena MJ, Nekrasov M, Mieszczanek J, Rybin V, Müller J, Evans P, Bienz M. 2008. Decoding of methylated histone $\mathrm{H} 3$ tail by the Pygo-BCL9 Wnt signaling complex. Mol Cell 30: 507-518.

Geng F, Wenzel S, Tansey WP. 2012. Ubiquitin and proteasomes in transcription. Annu Rev Biochem 81: 177-201.

Gieni RS, Hendzel MJ. 2009. Actin dynamics and functions in the interphase nucleus: Moving towards an understanding of nuclear polymeric actin. Biochem Cell Biol 87: 283-306.

Ha NC, Tonozuka T, Stamos JL, Choi HJ, Weis WI. 2004. Mechanism of phosphorylation-dependent binding of APC to $\beta$-catenin and its role in $\beta$-catenin degradation. Mol Cell 15: $511-521$.
Hamada F, Bienz M. 2004. The APC tumor suppressor binds to $\mathrm{C}$-terminal binding protein to divert nuclear $\beta$-catenin from TCF. Dev Cell 7: 677-685.

Hammoud SS, Cairns BR, Jones DA. 2013. Epigenetic regulation of colon cancer and intestinal stem cells. Curr Opin Cell Biol 25: 177-183.

Huber O, Krohn M, Kemler R. 1997. A specific domain in $\alpha$-catenin mediates binding to $\beta$-catenin or plakoglobin. J Cell Sci 110: 1759-1765.

Imajo M, Miyatake K, Iimura A, Miyamoto A, Nishida E. 2012. A molecular mechanism that links Hippo signalling to the inhibition of Wnt/ $\beta$-catenin signalling. EMBO J 31: 1109 1122.

Inge LJ, Rajasekaran SA, Wolle D, Barwe SP, Ryazantsev S, Ewing CM, Isaacs WB, Rajasekaran AK. 2008. $\alpha$-Catenin overrides Src-dependent activation of $\beta$-catenin oncogenic signaling. Mol Cancer Ther 7: 1368-1397.

Jeong WJ, Yoon J, Park JC, Lee SH, Kaduwal S, Kim H, Yoon JB, Choi KY. 2012. Ras stabilization through aberrant activation of $\mathrm{Wnt} / \beta$-catenin signaling promotes intestinal tumorigenesis. Sci Signal 5: ra30.

Ji H, Wang J, Nika H, Hawke D, Keezer S, Ge Q, Fang B, Fang X, Fang D, Litchfield DW, et al. 2009. EGF-induced ERK activation promotes CK2-mediated disassociation of $\alpha$-catenin from $\beta$-catenin and transactivation of $\beta$-catenin. Mol Cell 36: 547-559.

Kim SE, Huang H, Zhao M, Zhang X, Zhang A, Semonov MV, MacDonald BT, Zhang X, Garcia Abreu J, Poeng L, et al. 2013. Wnt stabilization of $\beta$-catenin reveals principles for morphogen receptor-scaffold assemblies. Science 340: 867870.

Kohler EM, Chandra SH, Behrens J, Schneikert J. 2009. $\beta$-Catenin degradation mediated by the CID domain of APC provides a model for the selection of APC mutations in colorectal, desmoids, and duodenal tumours. Hum Mol Genet 18: 213226.

Layton MJ, Faux MC, Church NL, Catimel B, Kershaw NJ, Kapp EA, Nowell C, Coates JL, Burgess AW, Simpson RJ. 2012. Identification of a Wnt-induced protein complex by affinity proteomics using an antibody that recognizes a sub-population of $\beta$-catenin. Biochim Biophys Acta 1824: 925-937.

Li J, Wang CY. 2008. TBL1:TBLR1 and $\beta$-catenin recruit each other to Wnt target-gene promoter for transcription activation and oncogenesis. Nat Cell Biol 10: 160-169.

Li VS, Ng SS, Boersema PJ, Low TY, Karthaus WR, Gerlach JP, Mohammed S, Heck AJ, Maurice MM, Mahmoudi T, et al. 2012. Wnt signaling through inhibition of $\beta$-catenin degradation in an intact Axin 1 complex. Cell 149: 1245-1256.

Lui C, Mills K, Brocardo MG, Sharma M, Henderson BR. 2012. APC as a mobile scaffold: Regulation and function at the nucleus, cytoplasm and mitochondria. IUBMB Life 64: 209-214.

McCartney BM, Näthke IS. 2008. Cell regulation by the Apc protein: Apc as master regulator of epithelia. Curr Opin Cell Biol 20: 186-193.

Perissi V, Scafoglio C, Zhang J, Ohgi KA, Rose DW, Glass CK, Rosenfeld MG. 2008. TBL1 and TBLR1 phosphorylation on regulated gene promoters overcomes dual CtBP and NCoR/ SMRT transcriptional repression checkpoints. Mol Cell 29: 755-766.

Phelps RA, Chidester S, Dehghanizadeh S, Phelps J, Sandoval IT, Rai K, Broadbent T, Sarkar S, Burt RW, Jones DA. 2009. A two-step model for colon adenoma initiation and progression caused by APC loss. Cell 137: 623-634.

Rai K, Sarkar S, Broadbent TJ, Voas M, Grossmann KF, Nadauld LD, Dehghanizadeh S, Hagos FT, Li Y, Toth RK, et al. 2010. DNA demethylase activity maintains intestinal cells in an 
Choi et al.

undifferentiated state following the loss of APC. Cell 142: 930-942.

Roberts DM, Pronobis MI, Poulton JS, Waldmann JD, Stephenson EM, Hanna S, Peifer M. 2011. Deconstructing the $\beta$-catenin destruction complex: Mechanistic roles for the tumor suppressor APC in regulating Wnt signaling. Mol Biol Cell 22: $1845-1863$.

Robinson BS, Moberg KH. 2011. Cell-cell junctions: $\alpha$-Catenin and E-cadherin help fence in Yap1. Curr Biol 21: R890-R892.

Rosenbluh J, Nijhawan D, Cox AG, Li X, Neal JT, Schafer EJ, Zack TI, Wang X, Tsherniak A, Schinzel AC, et al. 2012. $\beta$-Catenin-driven cancers require a YAP1 transcriptional complex for survival and tumorigenesis. Cell 151: 1457-1473.

Schlegelmilch K, Mohseni M, Kirak O, Pruszak J, Rodriguez JR, Zhou D, Kreger BT, Vasioukhin V, Avruch J, Brummelkamp TR, et al. 2011. Yap1 acts downstream of $\alpha$-catenin to control epidermal proliferation. Cell 144: 782-795.

Sierra J, Yoshida T, Joazeiro CA, Jones KA. 2006. The APC tumor suppressor counteracts $\beta$-catenin activation and $\mathrm{H} 3 \mathrm{~K} 4$ methylation at Wnt target genes. Genes Dev 20: 586-600.

Silvis MR, Kreger BT, Lien WH, Klezovitch O, Rudakova GM, Camargo FD, Lantz DM, Seykora JT, Vasioukhin V. 2011. $\alpha$-catenin is a tumor suppressor that controls cell accumulation by regulating the localization and activity of the transcriptional coactivator Yap1. Sci Signal 4: ra33.

Stamos JL, Weis WI. 2013. The $\beta$-catenin destruction complex. Cold Spring Harb Perspect Biol 5: a007898.

Su LK, Vogelstein B, Kinzler KW. 1993. Association of the APC tumor suppressor with catenins. Science 262: 1734-1737.

Su Y, Fu C, Ishikawa S, Stella A, Kojima M, Shitoh K, Schreiber EM, Day BW, Liu B. 2008. APC is essential for targeting phosphorylated $\beta$-catenin to the SCF $\beta \operatorname{TrCP}$ ubiquitin ligase. Mol Cell 32: 652-661.

Tsai BP, Hoverter NP, Waterman ML. 2012. Blending Hippo and WNT: Sharing messengers and regulation. Cell 151: 14011403.

Valenta T, Hausmann G, Basler K. 2012. The many faces and functions of $\beta$-catenin. $E M B O J$ 31: 2714-2736.

Vasioukhin V, Bauer C, Degenstein L, Wise B, Fuchs E. 2001. Hyperproliferation and defects in epithelial polarity upon conditional ablation of $\alpha$-catenin in skin. Cell 104: 605-617.

Wang Z, Song J, Milne TA, Wang GG, Li H, Allis CD, Patel DJ. 2010. Pro isomerization in MLL1 PHD3-bromo cassette connects $\mathrm{H} 3 \mathrm{~K} 4 \mathrm{me}$ readout to CyP33 and HDAC-mediated repression. Cell 141: 1183-1194.

Wray J, Hartmann C. 2012. WNTing embryonic stem cells. Trends Cell Biol 22: 159-168.

Yu FX, Guan KL. 2013. The Hippo pathway: Regulators and regulations. Genes Dev 27: 355-371.

Yu FX, Zhao B, Panupinthu N, Jewell JL, Lian I, Wang LH, Zhao J, Yuan H, Tumaneng K, Li H, et al. 2012. Regulation of the Hippo-YAP pathway by G-protein coupled receptor signaling. Cell 150: 780-791. 


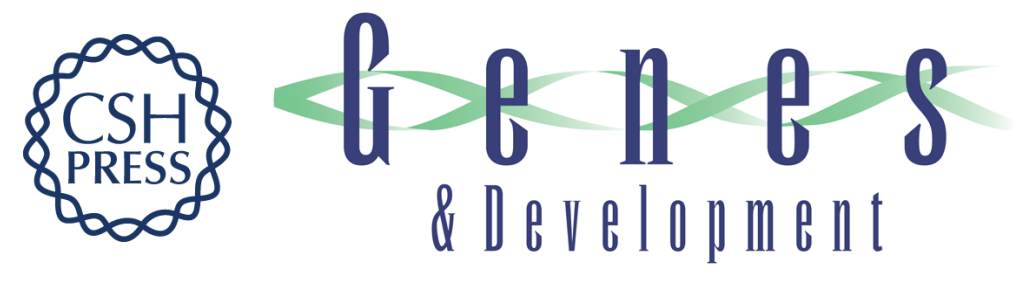

\title{
$\alpha$-Catenin interacts with APC to regulate $\beta$-catenin proteolysis and transcriptional repression of Wnt target genes
}

\author{
Seung H. Choi, Conchi Estarás, James J. Moresco, et al.
}

Genes Dev. 2013, 27:

Access the most recent version at doi:10.1101/gad.229062.113

\section{Supplemental http://genesdev.cshlp.org/content/suppl/2013/11/14/27.22.2473.DC1 Material}

References

This article cites 48 articles, 15 of which can be accessed free at: http://genesdev.cshlp.org/content/27/22/2473.full.html\#ref-list-1

Creative This article is distributed exclusively by Cold Spring Harbor Laboratory Press for the first Commons six months after the full-issue publication date (see

License http://genesdev.cshlp.org/site/misc/terms.xhtml). After six months, it is available under a Creative Commons License (Attribution-NonCommercial 3.0 Unported), as described at http://creativecommons.org/licenses/by-nc/3.0/.

Email Alerting Receive free email alerts when new articles cite this article - sign up in the box at the top Service right corner of the article or click here.

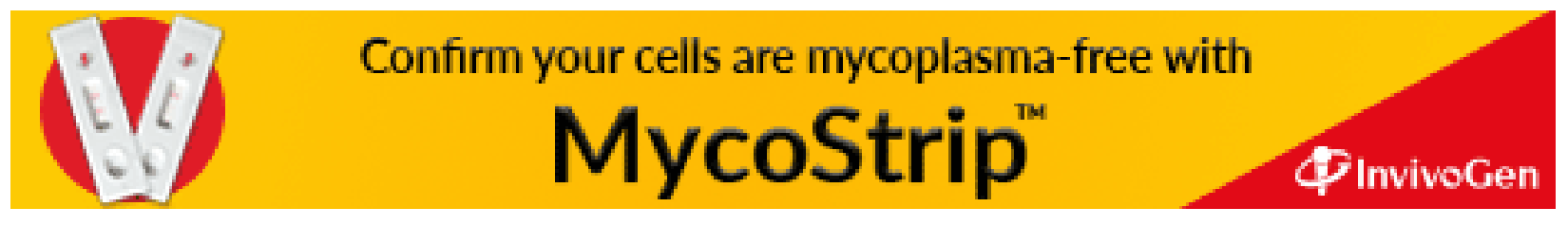

